\title{
EMPLEO, CALIDAD DEL EMPLEO Y SEGMENTACIÓN LABORAL EN ARGENTINA
}

\author{
Fabio Bertranou ${ }^{\dagger}$, Luis Casanova ${ }^{\dagger}$, \\ Maribel Jiménez ${ }^{\dagger \dagger}$, Mónica Jiménez ${ }^{\dagger \dagger}, 1$ \\ $\dagger$ OIT,
}

Recibido 10 Febrero 2014; aceptado 19 Junio 2014

\section{Resumen}

Este artículo examina para el caso de Argentina el fenómeno de la calidad del empleo y de la segmentación laboral durante las últimas dos décadas. Para ello se definen categorías laborales al interior del empleo asalariado formal, informal y del empleo independiente en función de diversos atributos que definen la calidad del empleo. Los resultados dan cuenta que la evolución del empleo de calidad no es ajena a los cambios en la política de protección del empleo, pero que responde en mayor medida a la política macroeconómica y laboral en su conjunto. Las estimaciones de brechas salariales no confirman la hipótesis de segmentación del empleo al interior del empleo asalariado informal y del informal, pero si entre estos dos grandes grupos.

Palabras clave: empleo informal, condiciones laborales, mercado laboral segmentado, movilidad laboral, brechas salariales.

Clasificación JEL: J31, J42, J80, O17.

\begin{abstract}
This article examines the phenomenon of job quality and labor segmentation over the past two decades in Argentina. To do this, job categories within the salaried formal employment, informal employment and self-employment are distinguished based on various attributes that define employment quality. The results show that the evolution of employment quality is no stranger to the political changes in employment protection, but responds more to macroeconomic and employment policy as a whole. Estimates of wage gaps do not confirm the hypothesis of segmentation of employment within the salaried formal and informal employment, but between these two groups.

Key words: informal employment, working conditions, segmented labor market, labor mobility, wage gap.

JEL Classification: J31, J42, J80, O17.

${ }^{1}$ Autora para correspondencia: monicajimenez@conicet.gov.ar. Este documento se basa en el informe país elaborado en el marco del proyecto "Employment and the quality of jobs: country case studies on labour market segmentation" de la Oficina Internacional del Trabajo (Bertranou et al. 2013b). Los autores agradecen los valiosos comentarios y sugerencias de Sandrine Cazes, Juan de Laiglesia, Marta Novik, Soledad Villafañe, Luis Beccaria, Juan Graña, Jorge Paz y a los participantes del ILO Research Workshop "Employment Quality in Segmented Markets" (diciembre de 2012). Las opiniones aquí expresadas pertenecen a los autores y no representan necesariamente las correspondientes a los organismos a los cuales se encuentran afiliados.
\end{abstract}

(C) Revista de Economía Laboral 


\section{Introducción}

La informalidad laboral es tan solo una faceta de la precariedad laboral, pero la misma representa uno de los principales déficits en cuanto a calidad del empleo en Argentina. En este sentido el análisis de la calidad del empleo en el país siempre ha girado en torno a la problemática de la informalidad. No obstante, en este estudio se define la calidad del empleo desde un enfoque más amplio que el de la ausencia de registración laboral. Además de la cobertura a la seguridad social se incluye otros atributos como la modalidad contractual, horas trabajadas y calificación de la tarea. Es decir que por empleo de calidad se entiende aquel trabajo que está registrado, celebra un contrato a tiempo indefinido, es de plena ocupación y requiere una alta calificación laboral (Rodgers, 1989; OIT, 2012). Así, la calidad de empleo se define considerando el enfoque conceptual de Trabajo Decente propuesto por la Organización Internacional del Trabajo (OIT) (OIT, 2002).

La evidencia empírica presentada en estudios previos da cuenta de la existencia de un fenómeno de segmentación del mercado de trabajo entre el empleo formal y el informal ${ }^{2}$ y también ha destacado la elevada movilidad laboral que existe entre estos dos segmentos ${ }^{3}$.

No obstante, enfoques teóricos, así como cierta evidencia empírica, indicarían que es posible que existan otros (sub)segmentos en el mercado de trabajo; tanto dentro del segmento formal como del informal. Por un lado, esto podría deberse a los efectos que tiene la flexibilización de las regulaciones para la protección del empleo en el margen al crear un segmento dentro de los empleos registrados con elevada rotación y en el que se registran los mayores ajustes frente a cambios en las condiciones económicas ${ }^{4}$. Por otra parte, también podría existir segmentación dentro del sector informal entre aquellos trabajadores de subsistencia y aquellos de mayor productividad relativa o que se desempeñan en unidades productivas vinculadas con la economía formal.

Tanto el contexto macroeconómico como las instituciones laborales son claves para comprender la evolución del empleo, su calidad y los patrones de segmentación. En relación a ambos aspectos, la experiencia

\footnotetext{
2 Ver Patrap y Quintín (2003), Beccaria et al. (2007), Alzúa (2008), Arias y Khamis (2008), Jiménez (2011), Paz (2013), entre otros, para obtener mayor detalle sobre la evaluación empírica del fenómeno de segmentación laboral en Argentina

${ }^{3}$ Ver Bertranou et al. (2013), Benítez et al., (2011) y Gasparini (2000), entre otros, para obtener un mayor detalle sobre el fenómeno de movilidad laboral en Argentina.

${ }^{4}$ Ver Cazes y Tonin (2009) y Galli y Kucera (2004), entre otros.
} 
argentina brinda, por los contrastes entre los esquemas macroeconómicos y en las instituciones laborales entre la década de 1990 y de los 2000s, un marco para analizar los efectos que tienen estos aspectos de política sobre la dinámica del empleo y su calidad así como sobre los patrones de movilidad y segmentación del mercado de trabajo.

En este marco, el objetivo general de este documento es examinar el fenómeno de la calidad del empleo y la segmentación laboral en el mercado de trabajo argentino y su relación con los cambios ocurridos en el período 1990-2011, particularmente los que tuvieron lugar en la política económica en general, y la política laboral en lo que hace a las regulaciones del mercado laboral.

El documento está estructurado de la siguiente manera. En la próxima sección se describen las bases de datos y las definiciones utilizadas en el análisis empírico. A continuación se presenta el marco conceptual a partir del cual se examinan los fenómenos de informalidad, precariedad y segmentación laboral en este documento. En la siguiente sección se analiza el contexto económico y de las instituciones laborales en Argentina durante 1990-2011 y su relación con los cambios ocurridos en la calidad del empleo y la segmentación laboral. Luego se exploran las hipótesis de segmentación laboral consideradas, examinando los patrones de movilidad y las brechas salariales que existen entre los distintos segmentos. Finalmente, la última sección presenta las conclusiones del documento.

\section{Datos y definiciones}

El análisis empírico presentado en este documento está basado en los microdatos provenientes de la Encuesta Permanente de Hogares (EPH), para el período 1995-2011. La EPH es un programa nacional de producción sistemática y permanente de indicadores sociales, que realiza el Instituto Nacional de Estadística y Censos (INDEC) en forma conjunta con algunas direcciones provinciales de estadística, desde 1974. El objetivo general de la EPH es conocer, mediante indicadores, un conjunto de dimensiones básicas que ayuden a caracterizar a la población desde el punto de vista demográfico (características demográficas básicas), por su participación en la producción de bienes y servicios (características ocupacionales) y por su participación en la distribución del producto social (características habitacionales, educacionales, del ingreso y migratorias). La encuesta se realiza en base a una muestra probabilística, estratificada, en dos etapas (selección de radios censales y selección de viviendas). La $\mathrm{EPH}$ en su modalidad denominada puntual (EPHP) se realizaba, desde 
1974, dos veces por año en mayo y octubre (ondas). El ámbito geográfico de cobertura de la encuesta siguió un plan de incorporación progresiva de la mayoría de las ciudades capitales de provincia y ciudades importantes ${ }^{5}$, llegando a cubrir 28 aglomerados en mayo de 1995. Luego, la cobertura geográfica se extendió a 31 aglomerados urbanos que representan al 70\% de la población urbana del país, al 91\% de la población que reside en centros urbanos de 50.000 y más habitantes y al $98 \%$ de la población que reside en centros urbanos de 100.000 y más habitantes. Además, en cada relevamiento (mayo y octubre) la muestra se renovaba en un $25 \%$.

En 2003, se implementó una reformulación metodológica integral de la EPH que ha dado lugar a la modalidad denominada continua (EPHC). Este cambio metodológico en la encuesta surgió como respuesta a las modificaciones recientes que tuvieron lugar en las características socioeconómicas de la población, en las modalidades de inserción en el mercado de trabajo así como en su dinámica de cambio y engloba tres aspectos principales: temáticos, muestrales y organizativos. La nueva $\mathrm{EPH}$ cuenta con cuestionarios rediseñados, aplicados en una muestra distribuida en el tiempo, bajo una modalidad de relevamiento continuo y con mayor frecuencia de presentación de resultados (INDEC, 2003). Los resultados de este relevamiento se publican trimestralmente. Actualmente el tamaño muestral es de 25.000 hogares por trimestre de los aglomerados urbanos que ya eran cubiertos por la antigua encuesta (EPHP) y en cada semestre, es de aproximadamente 29.000 hogares y 100.000 individuos.

Dado que la EPH fue modificada a partir del tercer trimestre del 2003, el período de análisis utilizando la EPHP, desde 1995 a mayo del 2003, se distingue del período cubierto por la EPHC desde el tercer trimestre de 2003 al cuarto trimestre del 2011. Es decir que para 19952003 se utilizan los datos provenientes del relevamiento puntual de la EPH y a partir del tercer trimestre del 2003 se utilizan los datos correspondientes al relevamiento continuo de esta encuesta. Por ello, es importante aclarar que las estimaciones provenientes de los datos de la $\mathrm{EPH}$ recabados en diferentes períodos pueden no ser estrictamente comparables debido a los cambios metodológicos implementados. No obstante, se utilizaron criterios de armonización entre la EPHP y la EPHC a fin de hacer más comparables los datos.

\footnotetext{
5 Algunos aglomerados fueron incluidos en la década del ochenta y otros, en los noventa. Los últimos aglomerados incorporados a la EPH fueron San Nicolás-Villa Constitución, Trelew-Rawson y Viedma-Patagones, en 2002.
} 
A partir de esta fuente de datos es posible cuantificar y caracterizar las inserciones laborales bajo la siguiente tipología basada en algunos atributos que definen la calidad del empleo. Para analizar esta última dimensión en este documento se consideran algunos de los factores que definen la calidad/precariedad de los empleos. En primer lugar, se realiza la distinción entre trabajadores asalariados, independientes profesionales e independientes no profesionales y el registro del empleo en la seguridad social. Estas dimensiones permiten realizar una primera distinción entre empleo formal e informal; conforme a los lineamientos adoptados en la $17^{\mathrm{ma}}$ Conferencia Internacional de Estadísticos del Trabajo (2003). Luego, por otra parte, se consideran otros atributos que definen a los empleos atípicos, analizando algunas de las formas arquetípicas de este tipo de empleo: el trabajo a término y el empleo a tiempo parcial involuntario.

Dentro del conjunto de los asalariados, se distingue entre:

1. asalariados formales (AF): asalariados registrados en la seguridad social; es decir, empleados que declaran en la EPH contar con descuentos jubilatorios. Se trata de asalariados con contratos registrados en el sistema de seguridad social.

1.1. asalariados formales en modalidades de contratación típicas AFMCT): asalariados formales con contrato a plazo indefinido. También se incluyen aquellos trabajadores que se desempeñan a tiempo parcial en forma voluntaria;

1.2.asalariados formales en modalidades de contratación atípicas (AFMCA): asalariados formales con contrato a plazo definido o que se desempeñan a tiempo parcial de manera involuntaria.

En general, un contrato laboral se considera a tiempo parcial involuntario (voluntario) cuando el ocupado declara estar trabajando menos de 32 horas semanales y desea (no desea) trabajar más horas ${ }^{6}$.

2. asalariados informales (AI): asalariados no registrados en la seguridad social, es decir, empleados sin descuentos jubilatorios. Se trata de asalariados sin contratos registrados en el sistema de seguridad social.

2.1.asalariados informales calificados (AIC): asalariados informales que se desempeñan en posiciones calificadas que

\footnotetext{
${ }^{6}$ Conforme a la legislación vigente, la dedicación horaria no puede superar las dos terceras partes de la jornada laboral habitual (esto es, 48 horas semanales).
} 
incluye a trabajadores profesionales y empleados dedicados a tareas técnicas u operativas.

2.2.asalariados informales no calificados (AINC): asalariados informales que se desempeñan en posiciones no calificadas.

A la vez, dentro de los AI, en algunos ejercicios de caracterización se analiza de manera separada al subconjunto del servicio doméstico.

3. Para el empleo independiente no es posible analizar la informalidad laboral bajo el mismo enfoque que el de los asalariados, pues la EPH no indaga respecto del cumplimiento de la normativa de la seguridad social por parte de los trabajadores independientes. Por ello se utiliza la denominada definición productiva ${ }^{7}$ de informalidad distinguiendo dentro del grupo de trabajadores independientes a:

3.1.patrones;

3.2.cuenta propias profesionales: cuentapropistas que se desempeñan en posiciones ocupacionales altamente calificadas, es decir, se dedican a tareas profesionales. Para el análisis, se los considera junto con los patrones (categoría ocupacional definida como CPPyP: cuenta propia profesional y patrones);

3.3.cuenta propias de oficio (CPO): cuentapropistas que se desempeñan en posiciones ocupacionales calificadas; es decir, desarrollan actividades de calificación técnica u operativa.

3.4.cuenta propias de subsistencia (CPS): cuentapropistas que se desempeñan en posiciones ocupacionales no calificadas.

Además de estas categorías ocupacionales, se consideran como ocupados formales (OF) a los AF, los CPPyP y al resto de los cuenta propias que se desempeñan en establecimientos del sector público o de más de 5 trabajadores. Mientras al resto de los ocupados se los considera como ocupados informales (OI). De este modo, la evolución de la composición del empleo en estas categorías laborales también describe la

\footnotetext{
7 La definición productiva califica como informales a los trabajadores que se desempeñan en puestos de baja productividad, que desarrollan actividades marginales de pequeña escala, generalmente basadas en la unidad familiar. Sin embargo, la implementación empírica de esta visión es complicada, debido a que, como señalan Gasparini y Tornarolli (2007), nociones como "productividad" son en verdad, inobservables y otras, como "actividades marginales" son difíciles de definir. Por ello, a partir de los datos de la EPH, la definición operativa de trabajador independiente informal adoptada en este estudio está asociada con el grado de calificación de la tarea.
} 
calidad de los empleos. En el gráfico 2.2 se expone en mayor detalle la caracterización interna de cada grupo y se analiza la hipótesis de segmentación entre ellos.

Con el objetivo de examinar la importancia de ciertas modalidades de trabajo dentro del empleo registrado como el trabajo de agencia, el empleo de duración determinada y el de duración indeterminada se utiliza la información proveniente de la Encuesta de Indicadores Laborales (EIL) ${ }^{8}$. Esta encuesta tiene como objetivo estudiar la evolución del empleo registrado en empresas de más de 10 ocupados, excluyendo al sector primario. La EIL define a los empleados registrados como aquellos ocupados registrados en el Sistema de Seguridad Social. El relevamiento de la EIL se realiza en forma mensual a cargo del Ministerio de Trabajo, desde diciembre de 1995. Con el objetivo de abarcar una serie histórica que cubra el período más prolongado, solo se considera el aglomerado del Gran Buenos Aires, dado que no existe disponibilidad de datos a nivel nacional para años previos a 1995. No obstante, el GBA es considerado el área urbana más grande de la Argentina ya que comprende al 34\% de la población total del país y genera el $60 \%$ del ingreso nacional.

\section{Informalidad, precariedad y segmentación laboral: Hipótesis de este documento}

La hipótesis de segmentación del mercado de trabajo tiene ya varios años de estudio. Sus raíces datan desde los trabajos seminales de Lewis (1954) y Harris y Todaro (1970). La estructura dual del mercado de trabajo está asociada con la presencia de dos grandes sectores, el primario y el secundario, entre los cuales existen importantes diferencias estructurales: el segmento primario engloba a los "buenos" empleos (de elevados salarios, estabilidad, oportunidades de avance, entrenamiento, etc.), mientras que el segmento secundario está conformado por los "malos" empleos (con salarios bajos, inestabilidad, escasas oportunidades de avance, etc.).

Particularmente, para los países de América Latina la estructura segmentada del mercado laboral ha estado tradicionalmente asociada a la informalidad laboral, aunque, durante la década de 1990, varios países de esta región modificaron sus regímenes laborales, siguiendo la lógica de que la flexibilización laboral mejoraría la competitividad, permitiendo la

8 Cabe aclarar que los datos de la EPH no se combinan con los de la EIL. Esta última encuesta sólo se utiliza en el análisis descriptivo de la composición del empleo registrado y de la creación neta de este tipo de empleo según modalidad contractual. 
aparición de formas "atípicas" de empleo que generan precariedad laboral $^{9}$ (Heckman y Pagés, 2005).

El empleo informal, los empleos atípicos y el empleo formal típico constituyen por lo tanto diferentes segmentos del mercado de trabajo, pero que están vinculados entre sí (Fields 2009, Rodgers, 1989). La informalidad laboral puede ser visualizada desde una doble perspectiva. La primera se ubica en una lógica de la sobrevivencia, donde el sector informal es el resultado de la presión del excedente de mano de obra por empleo, mientras que la segunda se asocia a la descentralización productiva, en la que la informalidad surge a partir de las estrategias de adaptación de las empresas a una demanda más inestable, que pueden incluir la contratación a través de formas promovidas, generando mayores posibilidades de evasión de obligaciones laborales (Tokman, 2001). No obstante, no toda actividad generada por la necesidad de sobrevivir es marginal o desconectada del resto del sistema, lo que también es obvio para aquellas que surgen producto de la descentralización o de modalidades que emergen para hacer frente a la competencia externa, y que por definición son funcionales a las grandes empresas (Tokman, 2001; Galli y Kucera, 2004). Así, se observa que existen puntos de intersección entre la problemática de la informalidad y la presencia de empleo atípicos.

A su vez, dentro del sector informal pueden existir diferentes segmentos, en los cuales los empleos tienen diferentes características. Fields (1990) sostiene que dentro del sector informal pueden existir dos segmentos: uno voluntario donde los puestos de trabajo son mejores o preferidos por sobre el empleo formal y un segmento donde el empleo informal es involuntario y de fácil acceso. Por su parte, Ranis y Stewart (1999) también presentan una teoría del sector informal con dos segmentos: uno tradicional de subsistencia y un sector moderno. Particularmente, la teoría sostiene que el sector más moderno o competitivo puede estar altamente integrado con la economía formal. Por ello, la extensión y características del sector informal puede depender de las características del sector formal; como su crecimiento, su competitividad, la posibilidad de subcontratar partes del proceso productivo, entre otros.

Por otra parte, otro segmento del mercado de trabajo que adquiere relevancia en los países de América Latina es el del empleo

\footnotetext{
9 La precariedad refiere a un concepto multidimensional que abarca aspectos en cierta forma relacionados como son la inestabilidad, la ausencia o insuficiencia de protección social, la inseguridad y la vulnerabilidad económica (Rodgers, 1989).
} 
independiente ${ }^{10}$. Este es altamente heterogéneo, pudiendo existir segmentos de empleo que pueden ser considerados como informales, como atípicos con algún nivel de precariedad, y como un empleo formal, estable y bien remunerado (Rodgers, 1989).

De este modo, el empleo informal, los empleos atípicos y algunas formas de empleo independiente tienen elementos causales comunes (como por ejemplo, la incapacidad de la economía de generar trabajo decente frente a la presión de la oferta, estrategias competitivas, otros) y una consecuencia común que es la precariedad.

\section{Gráfico 1: Informalidad laboral, empleos atípicos y nivel de desarrollo, 2010 ${ }^{(1)}$}

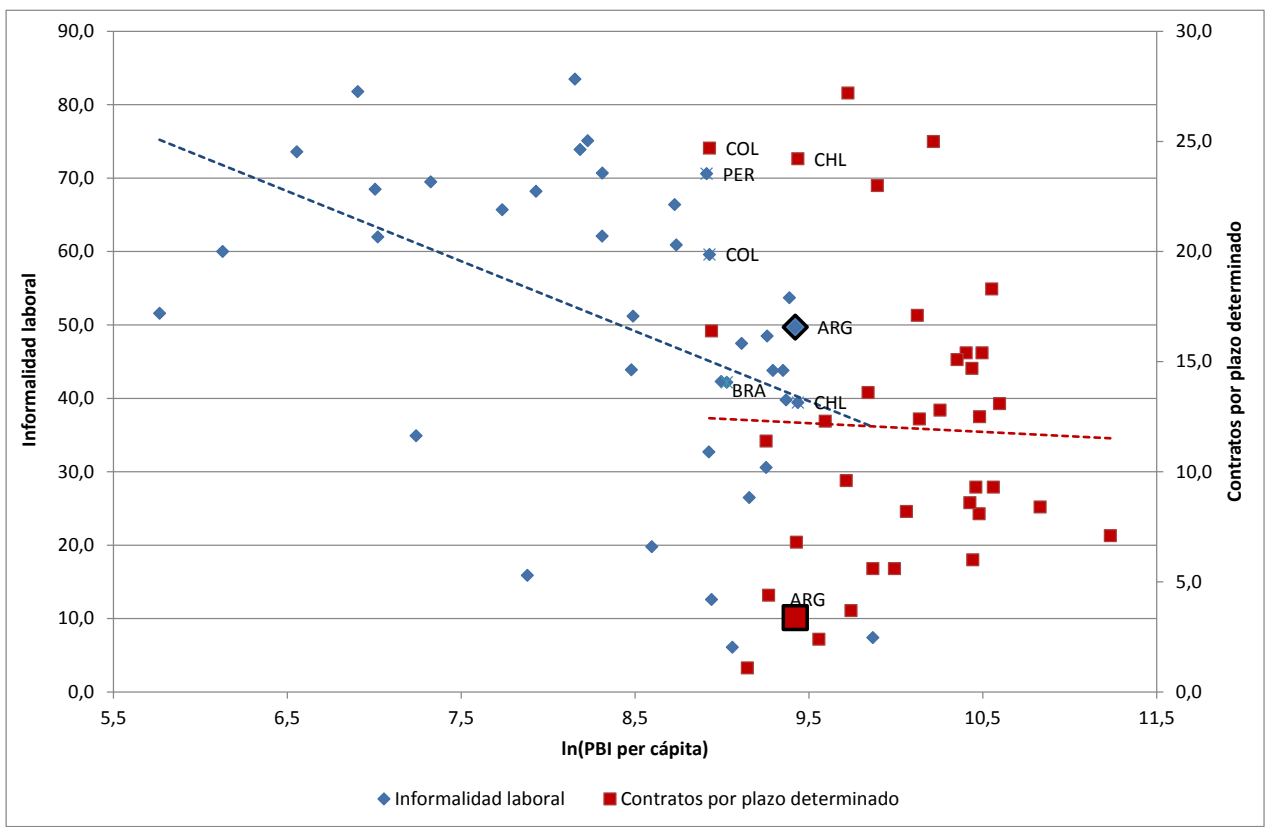

Nota: (1) El dato corresponde a 2010 o en caso contrario se presenta el último dato disponible. Fuente: elaboración propia sobre la base de datos de OIT (2011a), Eurostat, Heston et al. (2012). El dato del porcentaje de asalariados con contrato a plazo para Argentina, Chile y Colombia proviene de la Encuesta Permanente de Hogares (para los asalariados registrados), Fundación SOL (2012) (para los asalariados formales) y Urrea (2011) (para los asalariados formales de la industria).

10 Mientras que en Europa el empleo independiente se ubica en torno al 15\% del empleo total (EU, 2010) en América Latina representa cerca del 30\% del empleo total y en Argentina aproximadamente el 22\% (OIT, 2011b). 


\section{Gráfico 2: Hipótesis de movilidad y segmentación laboral para el mercado de trabajo en Argentina}

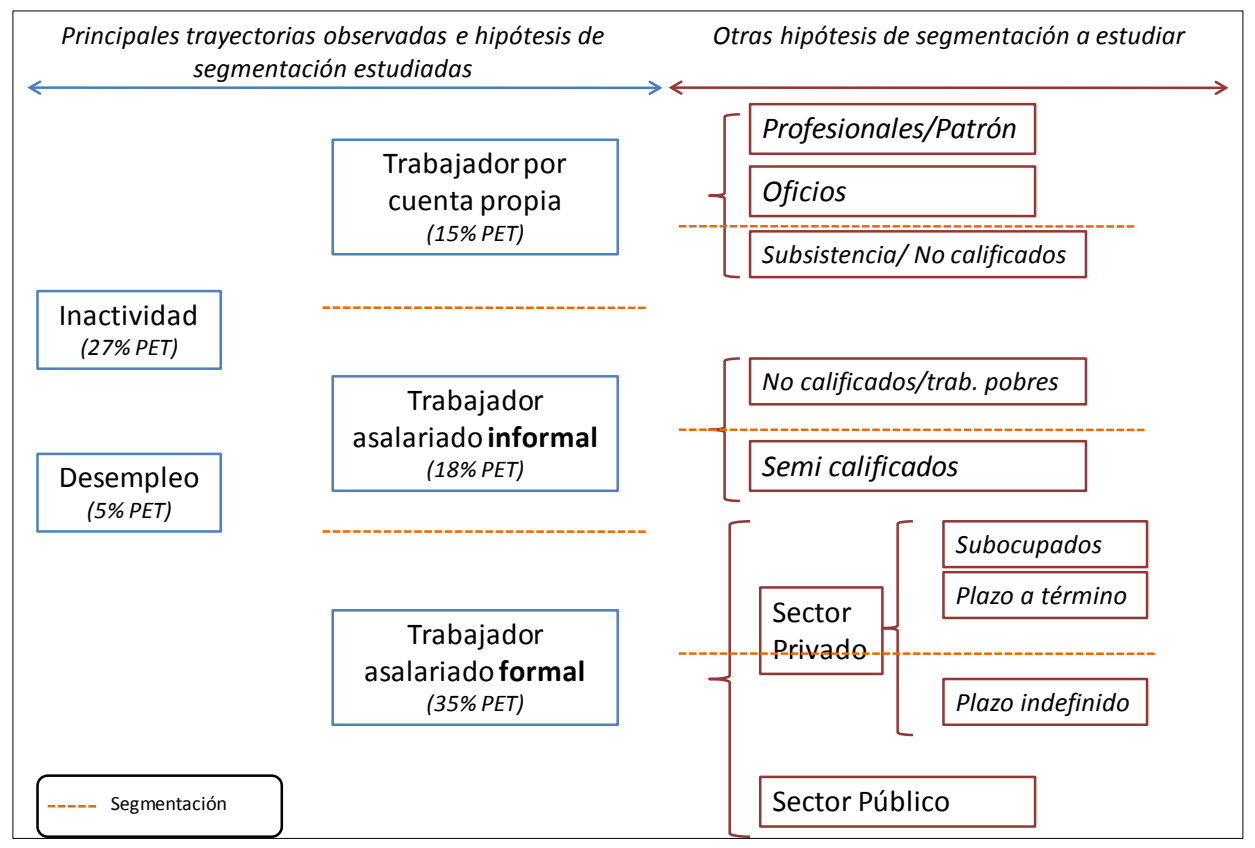

Nota: PET: Población en edad de trabajar (18-65 años).

Fuente: elaboración propia.

Para el caso de Argentina el fenómeno de la informalidad tiene una mayor incidencia que en otras economías de igual nivel de desarrollo (Gráfico 1). Asimismo, también existe una alta incidencia del empleo informal dentro de los trabajadores independientes (Bertranou y Maurizio, 2011).

Para cuantificar y analizar la calidad del empleo en Argentina se propone una tipología ad hoc de las inserciones laborales que incluye diversos elementos que han sido considerados en la literatura para definir la calidad del empleo. Entre estas dimensiones se considera, la existencia de una relación de dependencia, el registro del empleo en la seguridad social, la modalidad contractual, las horas trabajadas (subempleo involuntario) y la calificación de la tarea (relacionada con la productividad de la tarea desarrollada). Asimismo, sobre la base de esta misma clasificación se analizan los patrones de movilidad laboral entre estos segmentos así como la hipótesis de segmentación del mercado de trabajo a 
partir de las brechas de ingresos. El Gráfico 2 presenta este esquema de análisis.

\section{El contexto económico, las instituciones laborales y los cambios en la calidad del empleo en los 90s y en los 2000s}

Como se mencionó previamente, tanto el contexto macroeconómico como las instituciones laborales son claves para comprender la evolución del empleo, su calidad y los patrones de segmentación. Se considera que los cambios que tuvieron lugar en los esquemas macroeconómicos y en las instituciones laborales en la década de 1990 y de los 2000s tuvieron un efecto importante en la evolución de la calidad del empleo y la segmentación laboral en el mercado de trabajo argentino. Por esto, se analizan a continuación las relaciones existentes entre estos dos fenómenos y los cambios que tuvieron lugar en la política económica en general, y la política laboral durante 1993-2011.

A principios de la década de 1990 se estableció una política antiinflacionaria de anclaje cambiario conocida como la Convertibilidad. La configuración macroeconómica de este periodo se caracterizó por un tipo de cambio real apreciado, apertura comercial y financiera, que se complementaron con otras reformas "pro mercado" en distintos sectores de la economía (OIT, 2009). Esta política fue muy exitosa en materia antiinflacionaria, conduciendo a una rápida convergencia con la inflación internacional. Sin embargo, el mejor desempeño productivo registrado en los primeros años del nuevo modelo no pudo sostenerse a lo largo de toda la década, por el contrario el nivel de actividad exhibió una alta volatilidad debido, en parte, a la incapacidad del esquema de compensar shocks externos por medio de la flexibilidad nominal que otorga la política monetaria y cambiaria (Damill et al., 2011).

Si bien en 1991 y 1992 se observaron mejoras en el nivel de empleo (alcanzando la tasa de empleo a tiempo completo un pico máximo), esto no se sostuvo a lo largo de la década debido, entre otros aspectos, a los efectos que tuvieron en el mercado laboral algunos elementos del esquema macroeconómico, como la conjunción de apertura de comercial con un tipo de cambio apreciado (Damill et al., 2011). De este modo, durante los noventa la tasa de empleo se contrajo y, además, acompañó los ciclos económicos de crisis y recuperación. Por otra parte, la tasa de desempleo exhibió una tendencia creciente (con picos cercanos al 20\% en 1995 y 2002) debido de la incapacidad de la economía para generar empleos, en 
un contexto donde la tasa de actividad aumentaba (hasta la primera mitad de la década de 1990) producto de una mayor participación de las mujeres en el mercado de trabajo. Por esto, particularmente a mediados de los noventa, se desarrollaron reformas en el plano de las regulaciones laborales bajo la premisa que al otorgar mayor flexibilidad al mercado de trabajo se dinamizaría la demanda de empleo.

\section{Cuadro 1. Cambios en la normativa laboral, 1991 - 2011}

\begin{tabular}{|c|c|c|c|c|c|}
\hline \multirow[t]{2}{*}{ Normativa laboral } & \multirow{2}{*}{$\begin{array}{c}\text { Línea de base } \\
\text { (1990) }\end{array}$} & $\begin{array}{c}\text { Flexibilización } \\
\text { intensa }\end{array}$ & $\begin{array}{c}\text { Flexibilización } \\
\text { moderada }\end{array}$ & Crisis & $\begin{array}{c}\text { Nuevo } \\
\text { Régimen }\end{array}$ \\
\hline & & 1991 y 1995 & 1998 y 2000 & 2002 & 2004 \\
\hline \multicolumn{6}{|c|}{ A) Vinculada con contrato de tiempo indeterminado } \\
\hline Periodo de prueba & $\begin{array}{l}\text { No estaba explícito, } \\
\text { pero la } \\
\text { indemnización por } \\
\text { despido se pagaba a } \\
\text { partir de } 3 \text { los } \\
\text { meses de trabajo. }\end{array}$ & $\begin{array}{l}\text { 1995. Se introduce el } \\
\text { período de prueba ( } 3 \\
\text { a } 6 \text { meses). } \\
\text { Exenciones sobre } \\
\text { aportes y } \\
\text { contribuciones a la } \\
\text { seguridad social. }\end{array}$ & $\begin{array}{l}\text { 2000. Se extiende el } \\
\text { período a } 12 \text { meses } \\
\text { para las PyMEs. } \\
\text { Se eliminan } \\
\text { exenciones sobre } \\
\text { aportes y } \\
\text { contribuciones a la } \\
\text { seguridad social. }\end{array}$ & & $\begin{array}{l}\text { Se fija en } 3 \\
\text { meses. }\end{array}$ \\
\hline Indemnización & $\begin{array}{l}\text { Un mes por cada } \\
\text { año de servicio o } \\
\text { fracción mayor a } 3 \\
\text { meses (sin tope } \\
\text { sobre la base de } \\
\text { cálculo). } \\
\text { Monto de la } \\
\text { indemnización: no } \\
\text { puede ser menor a } 2 \\
\text { sueldos. }\end{array}$ & $\begin{array}{l}\text { 1991. Se incorpora } \\
\text { un tope sobre la base } \\
\text { de cálculo ( } 3 \text { salarios } \\
\text { de convenio, sin } \\
\text { antigüedad). }\end{array}$ & $\begin{array}{l}\text { 1998. Se reduce la } \\
\text { indemnización para } \\
\text { los trabajadores de } \\
\text { menor antigüedad. } \\
\text { Se reduce el } \\
\text { preaviso para } \\
\text { antigüedad menor a } \\
3 \text { meses. }\end{array}$ & $\begin{array}{l}2002 . \\
\text { Suspensión de } \\
\text { despidos por } \\
\text { causa } \\
\text { injustificada. } \\
\text { Doble } \\
\text { indemnización } \\
\text { (hasta 2007). }\end{array}$ & $\begin{array}{l}\text { 2004. Un mes } \\
\text { por cada año de } \\
\text { servicio o } \\
\text { fracción mayor } \\
\text { de } 3 \text { meses. } \\
\text { (el monto no } \\
\text { puede ser menor } \\
\text { a } 1 \text { sueldo). }\end{array}$ \\
\hline Aportes patronales & $33 \%$ & \multicolumn{2}{|c|}{$\begin{array}{l}\text { Durante la década de } 1990 \text { se realizaron } \\
\text { reducciones generales. La tasa legal } \\
\text { promedio descendió casi } 15 \text { p.p. en la década } \\
\text { de } 1990 .\end{array}$} & $\begin{array}{l}\text { 2002. Se } \\
\text { recomponen } \\
\text { parcialmente las } \\
\text { contribuciones } \\
\text { patronales. }\end{array}$ & $\begin{array}{l}23 \% \\
\text { (aproximado). } \\
\text { Reducciones } \\
\text { temporales para } \\
\text { nuevas } \\
\text { contrataciones. }\end{array}$ \\
\hline \multicolumn{6}{|c|}{ B) Vinculada con contrato de tiempo determinado } \\
\hline Plazo fijo & $\begin{array}{l}\text { Contrato a plazo } \\
\text { fijo: hasta } 5 \text { años; } \\
\text { con indemnización } \\
\text { al fin del contrato } \\
\text { ( } 50 \% \text { del régimen } \\
\text { general). Además } \\
\text { existen otras } \\
\text { modalidades: } \\
\text { eventual y de } \\
\text { temporada. }\end{array}$ & $\begin{array}{l}\text { 1991. Contrato de } \\
\text { tiempo } \\
\text { determinado. Plazo: } \\
6 \text { a } 24 \text { meses; } \\
\text { indemnización al } \\
\text { final del contrato } \\
\text { (medio sueldo); } \\
\text { cargas patronales } \\
\text { reducidas en un } 50 \% \text {. }\end{array}$ & $\begin{array}{l}\text { 1995. Se flexibiliza } \\
\text { el contrato de } \\
\text { tiempo } \\
\text { indeterminado para } \\
\text { las PyMEs. } \\
\text { 1998. Se deroga el } \\
\text { contrato por tiempo } \\
\text { determinado. }\end{array}$ & & \\
\hline $\begin{array}{l}\text { Otras modalidades } \\
\text { promovidas }\end{array}$ & & $\begin{array}{l}\text { 1991. Se crean } \\
\text { modalidades } \\
\text { promovidas. Plazo } \\
\text { determinado; sin } \\
\text { cargas patronales; } \\
\text { sin indemnización al } \\
\text { fin del contrato. }\end{array}$ & $\begin{array}{l}\text { 1995. Se modifican } \\
\text { las modalidades } \\
\text { promovidas } \\
\text { permitiendo un } \\
\text { mayor uso. } \\
\text { 1998. Se derogan las } \\
\text { modalidades } \\
\text { promovidas de } 1991 \\
\text { y } 1995 .\end{array}$ & & \\
\hline
\end{tabular}

Fuente: elaboración propia sobre la base de la legislación laboral vigente durante el periodo 1991-2011. 


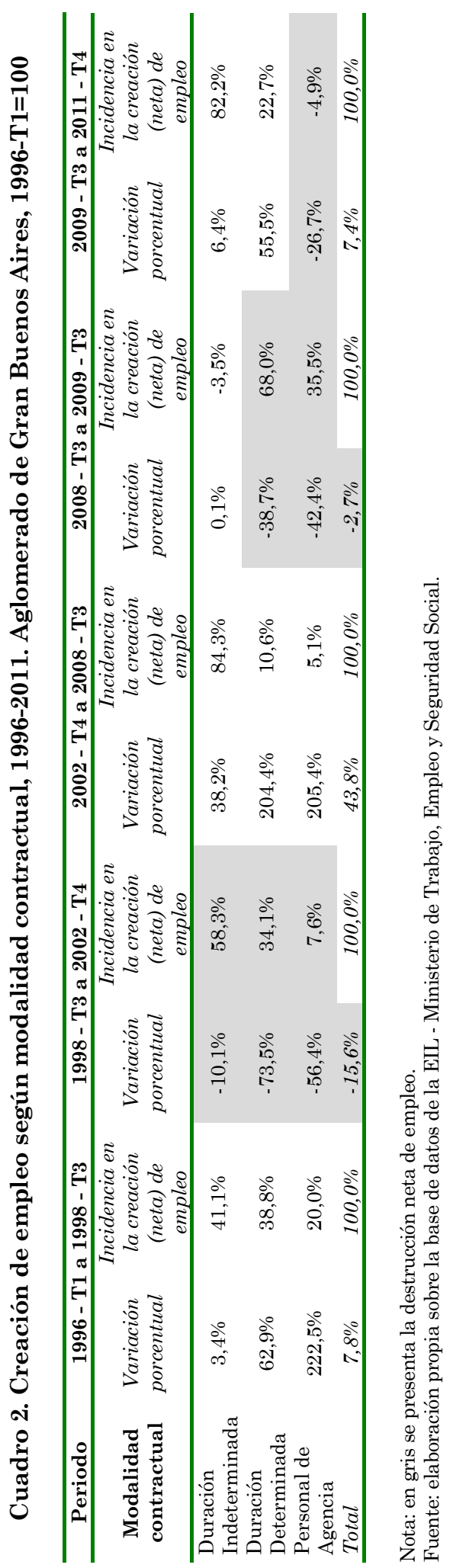


Las reformas al mercado de trabajo ocuparon un lugar central en la política económica. Bajo la influencia del Consenso de Washington, a través del cual se pregonaba por mercados laborales flexibles para acompañar reformas en otras áreas económicas, estas reformas se dieron en temas vinculados con la legislación de protección al empleo y el uso de contratos temporarios, pero también tocaron otros aspectos vinculados con los costos laborales (como es el caso de las contribuciones patronales a la seguridad social) y el rol de los sindicatos en las decisiones de las empresas sobre el uso de la fuerza de trabajo.

De este modo, en la década de 1990 se avanzó con una fuerte flexibilización laboral. Durante la primera mitad de esta década las principales políticas se vincularon con la introducción de una serie de contratos a plazo fijo con menores contribuciones patronales a la seguridad social y, en algunos casos, con menores costos de despido y finalización de contrato y la disminución en las alícuotas de aportes patronales a la seguridad social ${ }^{11}$.

Hacia finales de la década de 1990 se continuó con la política de reducción de contribuciones patronales pero se revirtieron las acciones de flexibilización del mercado laboral a través de la promoción de modalidades contractuales a término. No obstante, se flexibilizó la modalidad de contrato a plazo indefinido reduciendo el costo de la indemnización por despido y ampliando el periodo de prueba.

La economía tuvo su "luna de miel" en materia de creación de empleo a través de las modalidades de contrato a término durante el bienio 1996 y 1997. A pesar que las modalidades contractuales promovidas en el marco de la flexibilización laboral de los 90s nunca llegaron a representar un porcentaje significativo del stock total de trabajadores si tuvieron una participación destacable en la creación y destrucción de empleo. Durante el segundo periodo de expansión económica bajo la Convertibilidad (1996 al tercer trimestre de 1998) casi un $40 \%$ del empleo asalariado registrado creado (neto) se explica por el aumento de los puestos de trabajo bajo modalidades contractuales de duración determinada. En este periodo los contratos de duración determinada alcanzaron a representar un máximo de $8 \%$ del total del empleo asalariado registrado (Gráfico 3).

\footnotetext{
11 En 1993, se redujeron entre 30\% y 80\% las alícuotas de contribuciones patronales a la previsión social, al sistema de asignaciones familiares, al fondo nacional de empleo y al sistema de salud de los adultos mayores.
} 


\section{Gráfico 3. Tasas de crecimiento del Producto Interno Bruto y evolución del desempleo, 1991-2011}

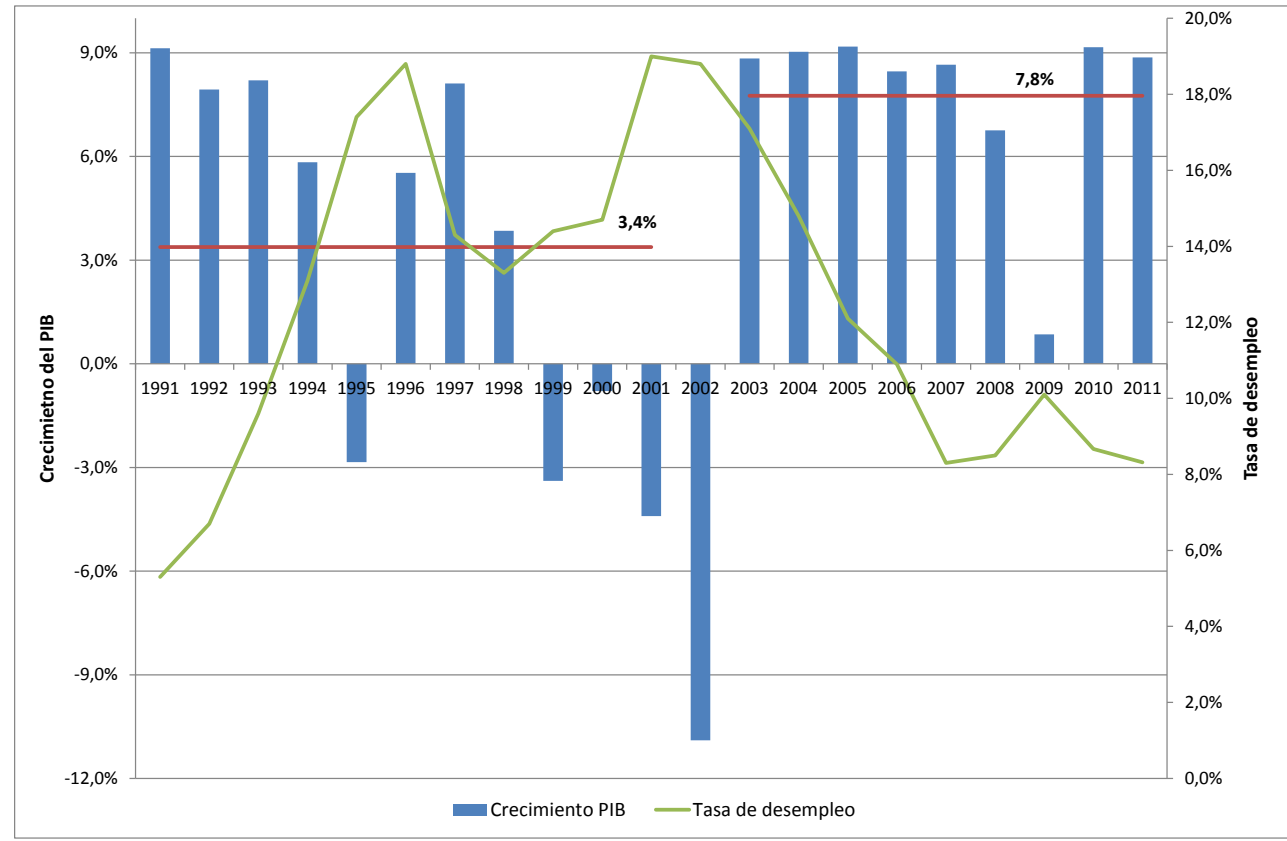

Nota: La tasa de desempleo corresponde al aglomerado urbano de Gran Buenos Aires. Fuente: elaboración propia sobre la base de datos del Ministerio de Economía y Finanzas Públicas y de la EPH -INDEC.

Una serie de shocks negativos, producto del contagio de las crisis internacionales (Rusia, Brasil y Turquía, en 1998, 1999 y 2000, respectivamente), sumados con una corrida contra la moneda local condujeron a una crisis económica, financiera, cambiaria y social en 2001. Así, entre el comienzo de la recesión en 1999 y 2002 el PIB registró una caída de 18,4\%. Asimismo, durante la recesión y crisis de la Convertibilidad (cuarto trimestre de 1998 al cuarto trimestre de 2002) la reducción del empleo bajo modalidades de contrato por plazo fijo explica el $34,1 \%$ de la caída del empleo mientras que la contracción del empleo por plazo indefinido explica el 58,3\% de la caída.

Luego de la crisis de 2001 se puso en marcha un régimen macroeconómico diferente al adoptado durante la década de 1990, que puede caracterizarse por la adopción de un esquema cambiario-monetario de flotación administrada del tipo de cambio orientado a preservar la 
competitividad externa, fomentar el crecimiento sostenido de la actividad económica en sectores transables no tradicionales y estimular mayores niveles de inversión y empleo a través de la expansión del mercado interno (MTEySS y OIT, 2012). Este nuevo esquema macroeconómico, implementado en un contexto internacional favorable hasta 2007, revirtió la tendencia contractiva del producto y generó elevadas tasas de crecimiento. Entre 2003 y 2011 se observó un crecimiento promedio de $7,8 \%$, a pesar de la desaceleración registrada en 2009 producto de la gran crisis internacional y de la importante sequía que afectó al sector agropecuario en ese mismo año.

A partir de 2003, con la recuperación de la actividad económica, la tasa de empleo aumentó de manera sostenida hasta 2007 cuando ingresa en una fase de amesetamiento, conforme el descenso paulatino de la elasticidad empleo producto (MTEySS y OIT, 2012). En este período el empleo fue colocado en el centro de las políticas públicas. En este nuevo contexto, se reactivaron instancias de discusión salarial como la negociación colectiva y el salario mínimo, se fortaleció la fiscalización del empleo, se implementaron un conjunto de políticas activas de empleo y se modificaron diversos aspectos de la legislación laboral (MTEySS, 2010). En relación a esto último, se sancionó un nuevo régimen laboral que revirtió las tendencias flexibilizadoras en la política laboral y durante los años donde el nivel de desempleo se ubicó por encima del 10\%, se aumentó el monto de la indemnización por despido para proteger a los trabajadores ocupados. Asimismo, se incrementaron las alícuotas de contribuciones patronales, pero en un nivel considerablemente inferior al de principios de la década de 1990, y se realizaron políticas de reducciones temporales para fomentar la creación de empleo formal. Estas acciones fueron acompañadas por diferentes políticas de mercado de trabajo destinadas a mejorar las condiciones de empleabilidad de los trabajadores desocupados y ocupados en la economía informal.

Por último, el Ministerio de Trabajo mejoró el enforcement de las leyes laborales al recuperar sus competencias para controlar y fiscalizar el cumplimiento de la normativa de la seguridad social en todo el territorio nacional. De este modo, de manera coordinada con los gobiernos provinciales y otras instituciones del gobierno nacional, se avanzó en la detección del empleo no registrado (Bertranou et al., 2013a).

Asimismo, durante este período, que siguió a la crisis de la Convertibilidad, la etapa de crecimiento del empleo registrado se caracterizó por el aumento del empleo bajo modalidad de plazo por tiempo indefinido. Esta modalidad contractual explica el 84,3\% de la creación neta de empleo entre el primer trimestre de 2003 al tercer trimestre de 
2008 (Cuadro 4). En 2009 el crecimiento del empleo se ve interrumpido por el efecto de la crisis financiera internacional en la economía doméstica. Sin embargo, la destrucción neta de empleo se da en las modalidades de trabajo de agencia y contratos por tiempo determinado. Superada la crisis internacional, el empleo por plazo indefinido vuelve a explicar casi la totalidad de la creación neta de empleo.

\section{Gráfico 4. Evolución del empleo asalariado informal y a tiempo completo - estable según tamaño del establecimiento, 1995, 2011}

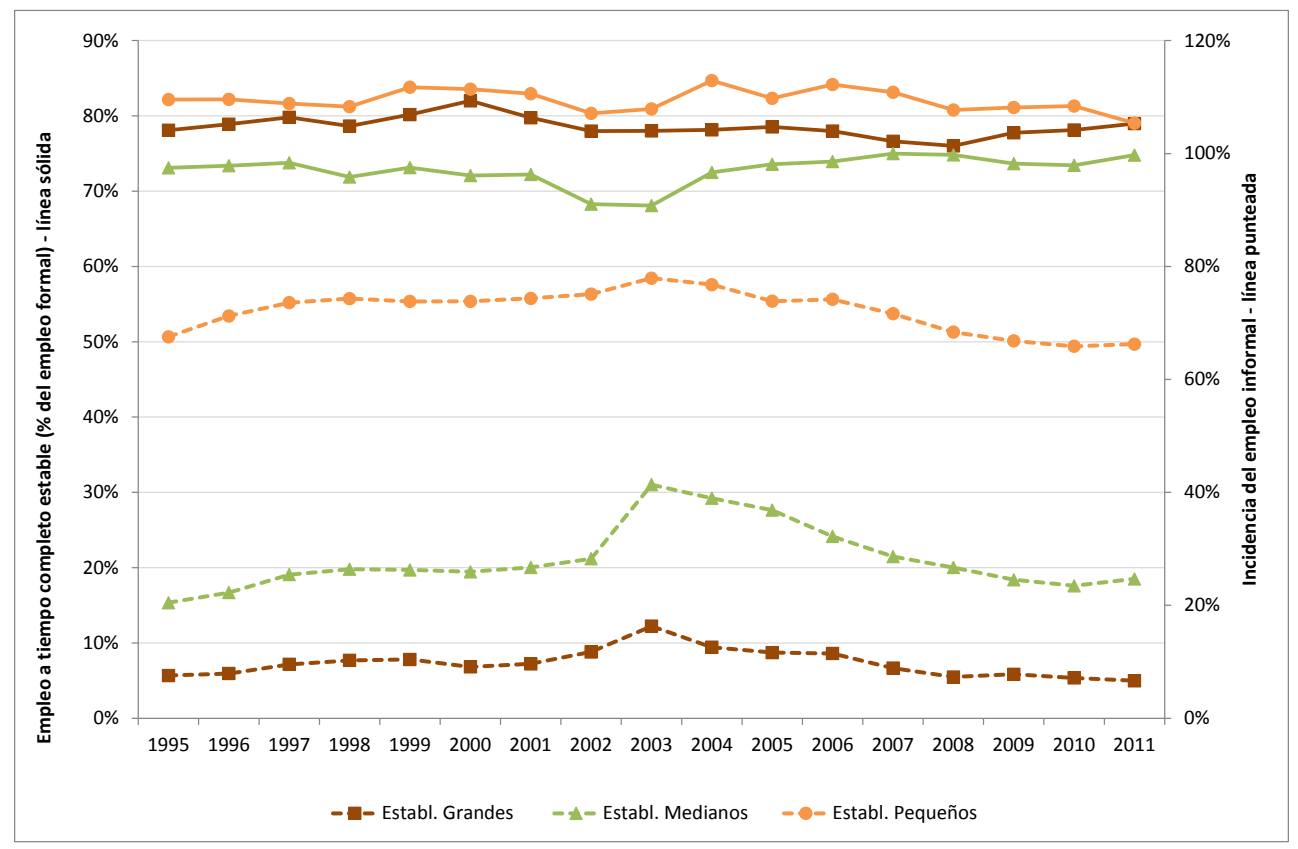

Nota: se consideran establecimientos pequeños a los que tienen menos de 6 empleados; establecimientos medianos a los de entre 6 y 100 empleados y establecimientos grandes a los que tienen más de 100 empleados.

Fuente: elaboración propia sobre la base de datos de la EPH-INDEC.

Estas modalidades contractuales flexibilizadoras del mercado laboral son utilizadas en mayor medida por los establecimientos de mayor tamaño. En los establecimientos medianos y grandes se aprecia una menor proporción de trabajadores estables a tiempo completo, es decir, se 
utilizan las modalidades promovidas con mayor intensidad (en especial durante la década de 1990). En las firmas pequeñas la flexibilidad proviene principalmente del empleo informal. En los establecimientos de tamaño medio se ha registrado la mayor sensibilidad en lo que respecta tanto a destrucción de empleo estable a tiempo completo y aumento de la informalidad en los años noventa, como a creación de empleo y reducción de la informalidad en los 2000s (Gráfico 4). En 2011, las diferencias en el porcentaje del empleo asalariado registrado con un contrato estable a tiempo completo según tamaño de establecimiento son menores que las observadas con anterioridad, sin embargo, las diferencias en la incidencia del empleo no registrado continúan siendo muy elevadas.

Gráfico 5. Composición del empleo según tipo de inserción laboral, 1995-2011

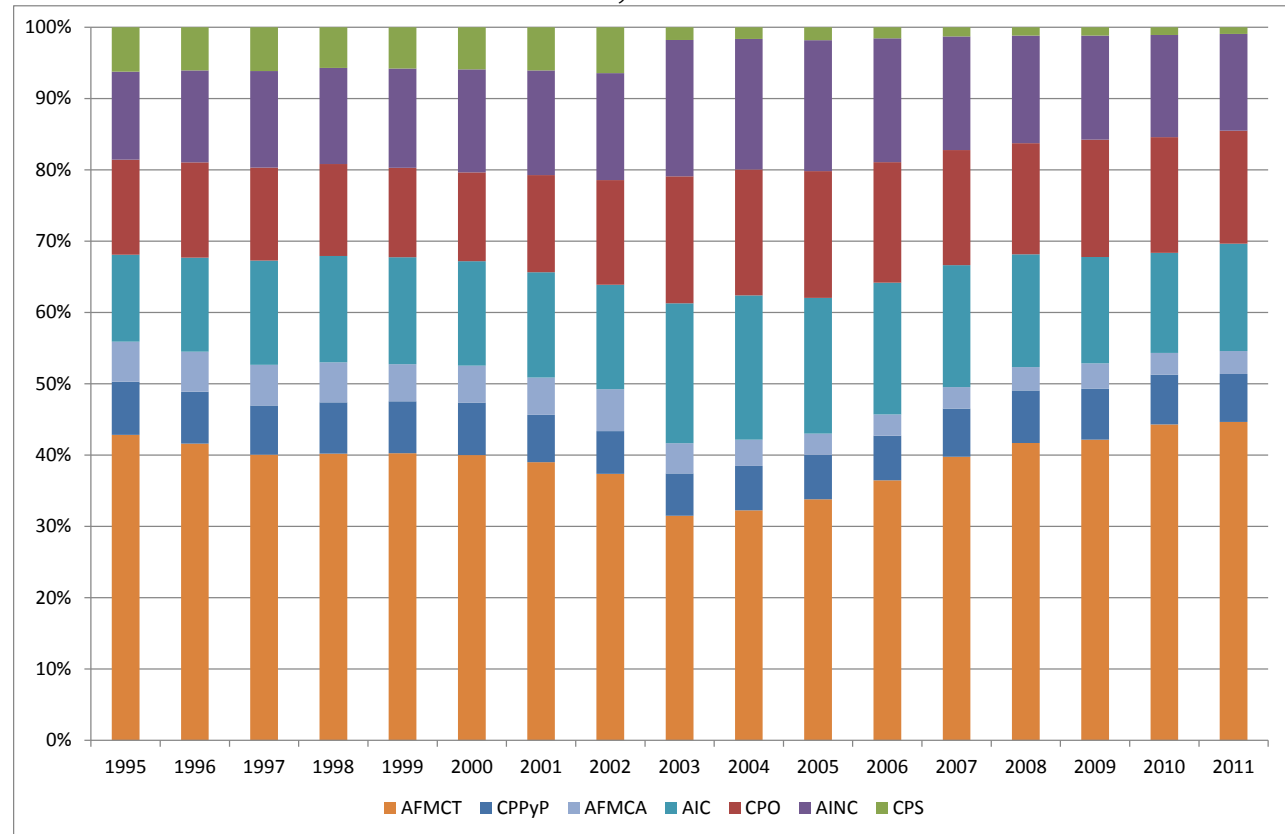

Fuente: elaboración propia sobre la base de datos de la EPH-INDEC.

Los contrastes entre los 90 s y los 2000s no solo se dan en relación a nivel de empleo generado sino también en su calidad. Los cambios en la composición del empleo según las categorías laborales consideradas para 
evaluar distintas hipótesis de segmentación del mercado de trabajo, también dan cuenta de la evolución ocurrida en la calidad del empleo.

Considerando a los AFMCT como aquellos trabajadores que se desempeñan en los mejores empleos, se observa que en los 2000s se produce una reversión en la tendencia decreciente que registraba el porcentaje de trabajadores en esta categoría. Entre 1995 y 2003 este porcentaje cayó de $40,4 \%$ al $30 \%$ y luego creció hasta ubicarse en $41,3 \%$ en 2011. Este incremento de participación obedece a diversos cambios en la estructura de empleo; el principal es la caída en el empleo asalariado no registrado (AI) seguido por un descenso del empleo independiente no profesional (CPO y CPS), que redujeron su participación en 10,4 p.p. y 3,1 p.p., respectivamente.

Gráfico 6. Composición del empleo asalariado registrado del sector privado según modalidad contractual, 1995-2011 Total aglomerados urbanos - EPH / Aglomerado de Gran Buenos Aires - EIL ${ }^{(1)}$

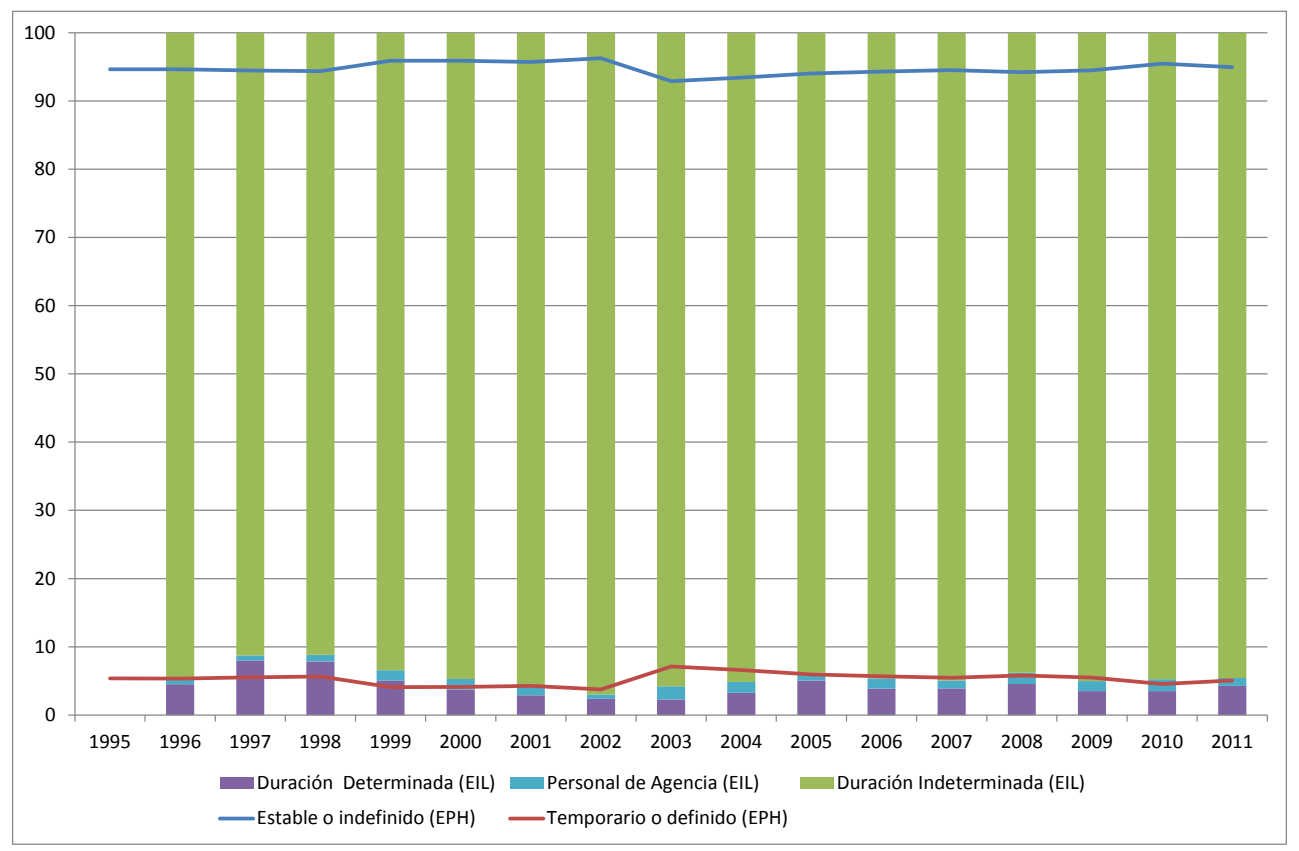

Nota: (1) (EPH) hace referencia a información proveniente de la Encuesta Permanente de Hogares y (EIL) hace referencia a información proveniente de la Encuesta de Indicadores Laborales (encuesta a empresas).

Fuente: elaboración propia sobre la base de datos de la EIL - Ministerio de Trabajo, Empleo y Seguridad Social y la EPH - INDEC. 
En el conjunto de trabajadores asalariados, la tasa de incidencia del empleo no registrado descendió de 49,1\% en 2003 a 34,5\% en 2011 . Por otra parte, entre los trabajadores independientes la incidencia del no registro parece haber descendido en menor medida, ubicándose en 2010 en torno al 58\%. De esta forma, para toda la fuerza de trabajo ocupada, es decir incluyendo asalariados e independientes, el nivel de no registro alcanzaría el 43.8\% (Bertranou et al., 2013a).

Entre los trabajadores asalariados formales, considerando la modalidad contractual y la dedicación horaria, la inserción más frecuente es el empleo estable (a plazo indefinido) a tiempo completo. La información proveniente de la Encuesta Permanente de Hogares (EPH) y de la Encuesta de Indicadores Laborales (EIL) revela el bajo peso que tienen los contratos a plazo definido dentro del empleo formal (Gráfico 6).

Entre los trabajadores asalariados informales se observa una composición casi igualitaria entre trabajadores calificados/semicalificados (AIC) y no calificados (AINC). Dentro de este grupo la subocupación es elevada, alcanzando en 2011 al 42,2\% de estos trabajadores. Otro aspecto a considerar es que casi el $60 \%$ considera al empleo como estable, a pesar que no se encuentra registrado en la seguridad social. Por otra parte, 1 de cada $4 \mathrm{AI}$ se desempeña como empleado doméstico.

Por último, entre los trabajadores independientes predominan los cuenta propias de oficio (CPO), que en 2011 representan al 67\% del total de trabajadores independientes, seguidos por los profesionales y patrones (CPyP) y los cuenta propias de subsistencia (CPS).

\section{Segmentación laboral en los 90s y en los 2000s}

En esta sección se analiza la hipótesis de segmentación laboral durante los 90s y los 2000s. Con este objetivo, se estiman patrones de movilidad laboral y brechas de ingresos entre las categorías ocupacionales consideradas, con el objetivo de identificar aquellas entre las que se observa evidencia a favor de las hipótesis de segmentación planteadas en el Gráfico 2.

\subsection{Rotación y movilidad laboral}

La prueba definitiva de la hipótesis de un mercado laboral requiere comprobar si los individuos pueden desplazarse libremente entre los segmentos o enfrentan barreras a la entrada en algunos (Maloney, 2004). Por ello se analizan a continuación los patrones de movilidad y la 
rotación laboral entre las categorías laborales definidas en el Gráfico 2 para evaluar las hipótesis de segmentación postuladas.

Los patrones de rotación y movilidad de los grupos considerados en el análisis presentan marcadas diferencias entre la década de 1990 y los 2000s. Entre los asalariados formales se aprecia una menor rotación en los 2000s para aquellos AFMCT mientras que se aprecia una mayor rotación entre los trabajadores AFMCA. En el primer caso obedece, principalmente, a una reducción de la tasa de salida mientras que en el segundo caso, tanto a una mayor tasa de salida como de entrada ${ }^{12}$.

Entre los trabajadores informales se observa una menor tasa de rotación en los 2000s, principalmente entre los no calificados. Esto responde a una reducción en la tasa de entrada, y entre los no calificados también a una menor tasa de salida.

Entre los trabajadores independientes, para los 2000s, se registra una menor tasa de rotación en los trabajadores de oficios y una mayor tasa de rotación entre los trabajadores de subsistencia. En el primer caso obedece a una menor tasa de entrada como de salida mientras que en el segundo caso, principalmente, a una mayor tasa de entrada y de salida.

En línea con lo que se observa a partir de las tasas de rotación, las trayectorias laborales seguidas por los asalariados formales muestran una tendencia hacia una mayor estabilidad en los 2000s en los empleos registrados, estables y a tiempo completo o a tiempo parcial voluntario $(\mathrm{AFMCT})^{13}$. Los nuevos trabajadores asalariados formales con empleo estable y a tiempo completo o tiempo parcial voluntario provienen de otras ocupaciones más que del desempleo y la inactividad. Se advierte un importante flujo de movilidad entre los empleos AFMCA y AFMCT y entre los primeros y los AIC. Particularmente, durante la década de 1990 provenían, en mayor proporción, del empleo asalariado registrado a plazo o a tiempo parcial involuntario (AFMCA) y en los 2000s provienen principalmente del empleo asalariado no registrado calificado (AIC).

\footnotetext{
12 La tasa de entrada es la relación porcentual entre la cantidad de nuevos puestos en una ocupación particular de un año a otro y la cantidad de ocupados en un determinado puesto laboral a inicios del año. La tasa de salida es la relación porcentual entre la cantidad de egresos desde una ocupación a otra durante un año y la cantidad de ocupados en un determinado puesto laboral en el año inicial. La tasa de rotación en cada ocupación se computa como el promedio entre la tasa de entrada y salida correspondiente.

13 Ver Anexo 1 para mayor detalle.
} 


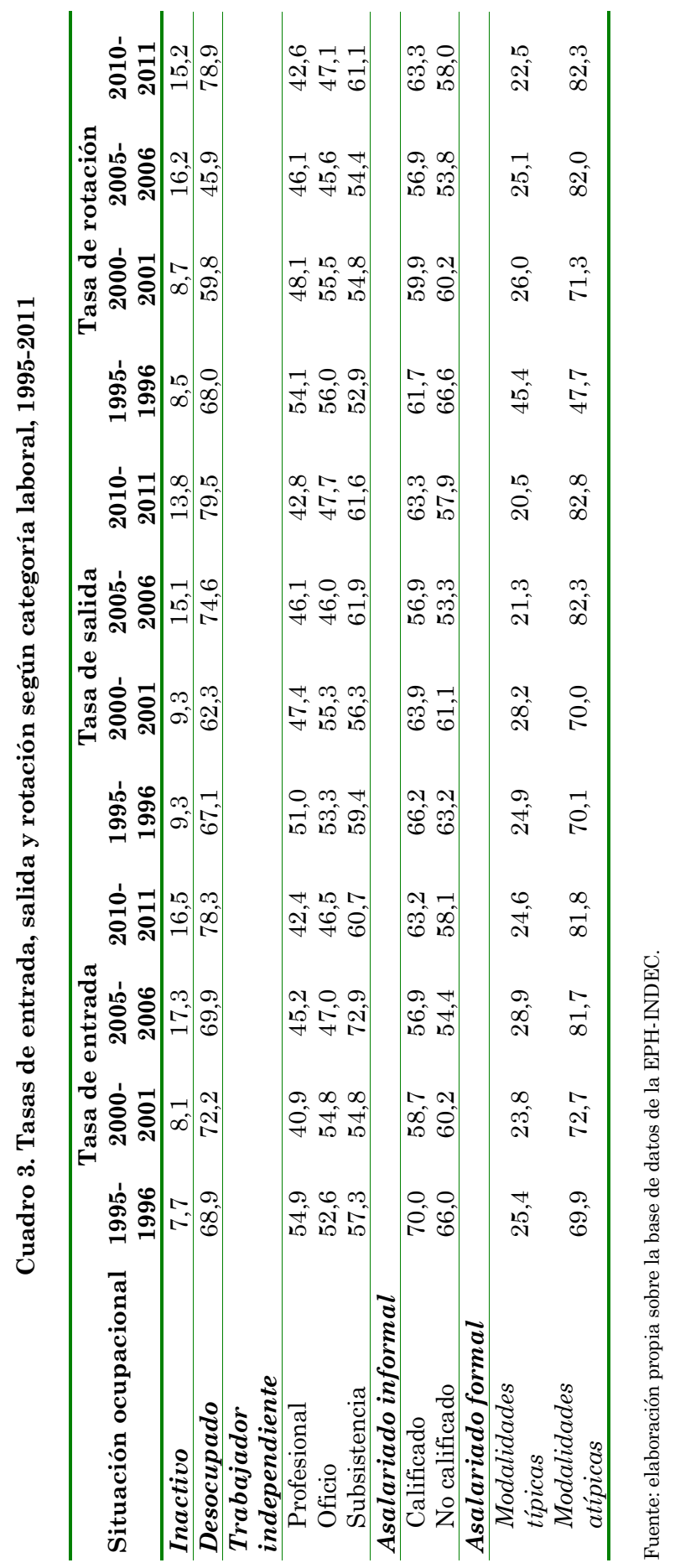


Entre los asalariados informales, la mayoría de los no calificados (AINC) que realiza transiciones se dirige hacia la desocupación o inactividad mientras que el resto transita entre ocupaciones. El porcentaje de trabajadores que permanece al menos un año en el empleo AINC no llegó al 50\% en todo el periodo considerado (Anexo 1).

Entre los trabajadores AIC se aprecia una tasa de permanencia en la condición aun inferior a la de los AINC (48\% o menos de los trabajadores en esta condición permanece en la misma condición durante un año). Los calificados presentan un menor vínculo con la inactividad y con el desempleo y mayor vínculo con otro tipo de inserción laboral. Particularmente, el destino de aquellos que abandonan empleos AIC es, en primer lugar, el empleo AFMCT, principalmente en los 2000s. Este tipo de inserción es seguida por el empleo AINC y por el cuentapropismo de oficio (Anexo 1).

Por último, las trayectorias laborales seguidas por los cuentas propias de oficio y subsistencia dan cuenta que la mayoría de los que dejan su puesto se dirigen hacia otras ocupaciones, es decir, no salen del mercado laboral. El principal destino de los CPO que abandonaron esta categoría laboral, luego de un año, es un puesto asalariado informal calificado (AIC). Por su parte, el principal destino de los CPS que dejaron esta categoría laboral es el CPO. Los vínculos entre el CPO y el empleo AIC se refuerzan cuando se observa que el segundo tipo de empleo es el principal origen del nuevo empleo CPO. Por su parte, entre los CPS la categoría laboral de origen más importante en 1995 era un empleo AINC, pero durante los 2000s el empleo independiente como CPO ha sido el principal origen (Anexo 1).

A fin de realizar una valoración definitiva de la intensidad de los flujos entre las categorías laborales consideradas, se estandarizan las probabilidades de transición, ajustándolas por el tamaño del sector de destino ${ }^{14}$. A partir de estas tasas de transición estandarizadas es posible determinar si los flujos hacia una categoría particular son especialmente altos o bajos comparados con los que surgirían si los trabajadores se movieran aleatoriamente entre los sectores. Además, el análisis de la existencia de simetría en los flujos entre dos categorías laborales, puede sugerir si los flujos tienden a ser unidireccionales o bidireccionales (Maloney, 1999). Los resultados obtenidos de este ejercicio confirman en general, los hechos estilizados sobre las trayectorias laborales previamente mencionadas (Anexo 1). Así, se constatan importantes flujos entre los puestos AFMCT y AFMCA durante todo el período analizado,

14 Ver en el Anexo 3 los detalles metodológicos. 
con mayor intensidad de los desplazamientos desde ésta última categoría laboral hacia la primera.

$\mathrm{Al}$ interior del trabajo informal no se observa simetría de los flujos entre los puestos calificados y no calificados. Los AINC se dirigen con mayor intensidad hacia la desocupación y las ocupaciones asalariadas informales calificadas. Sin embargo, a diferencia de lo que se advierte a partir de las probabilidades de transición no estandarizadas, los AINC presentan un flujo importante hacia el empleo independiente como CPS que disminuye su intensidad a lo largo del período analizado. En tanto que, entre los AIC, los flujos más importantes ocurren hacia el empleo independiente como CPO y hacia las ocupaciones asalariadas formales atípicas. El primero, con mayor intensidad en 1995 y el segundo, en los 2000s.

Por otra parte, entre las distintas categorías de trabajo independiente se registran movimientos bidireccionales aunque de distinta intensidad. Así, se aprecian importantes flujos entre los CPO y $\mathrm{CPPyP}$, pero con mayor fuerza desde los primeros hacia los segundos en algunos años.

\subsection{Brechas salariales}

La hipótesis central de la literatura de mercados laborales segmentados es que cada segmento del mercado laboral tiene un mecanismo diferente de determinación salarial, por lo cual individuos comparables obtienen salarios distintos. Pero, para que las brechas salariales impliquen la existencia de un mercado de trabajo segmentado la movilidad laboral entre sectores debe ser baja (Taubman y Wachter, 1986).

Así, siguiendo la literatura empírica, a continuación se analizan el diferencial de salarios ${ }^{15}$ entre las categorías laborales previamente

\footnotetext{
15 Para estimar estas brechas salariales se considera el ingreso mensual de la ocupación principal. Dado que algunas actividades en el mercado laboral tienen restringidas las horas de trabajo, se considera que los ingresos laborales mensuales reflejan mejor las oportunidades de ingresos que los ingresos horarios. Además, la información recogida por la EPH dificulta el cálculo correcto del ingreso horario. El problema se deriva de la inconsistencia temporal de la información necesaria para tales fines; por un lado, los datos de ingresos laborales provienen del mes anterior al relevamiento y por el otro, se presenta información sobre las horas trabajadas durante la semana de referencia, posterior a la percepción de los ingresos. Por otra parte, como la EPH no indaga al ocupado sobre el monto de su ingreso laboral bruto o neto se asume, en general, que el ingreso reportado por los trabajadores es el neto y no el bruto dado que es más probable que el asalariado recuerde y declare su ingreso neto de impuestos laborales.
} 
determinadas: AFMCT, AFMCA (ambos componen a los asalariados formales), AIC, AINC (ambos componen a los asalariados informales), CPOyS y CPPyP (ambos componen a los trabajadores independientes).

\section{Gráfico 7. Brechas brutas de ingresos entre trabajadores asalariados en distintas inserciones laborales. 1995-2011 En relación a los AFMCT}

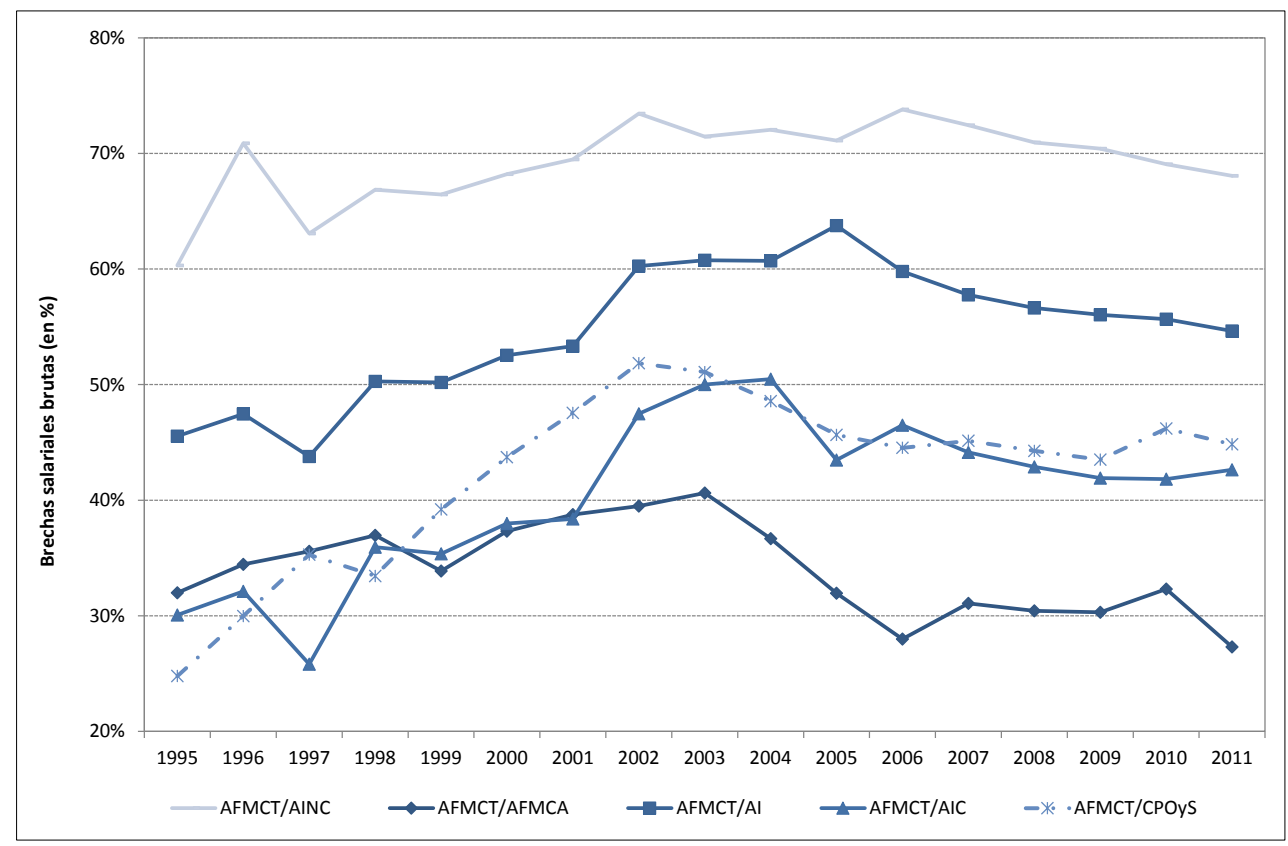

Nota: no se presenta la brecha con los CPPyP debido a que la misma es tan amplia que dificulta que el resto de las brechas sean apreciadas si se presentan todas en un mismo gráfico. Fuente: elaboración propia sobre la base de datos de la EPH-INDEC.

Como primera aproximación se presentan las brechas salariales brutas $^{16}$ entre las diferentes categorías ocupacionales consideradas, en relación a los asalariados formales contratados a plazo indefinido a tiempo completo o a tiempo parcial voluntario (AFMCT). La evolución de estos diferenciales de ingresos dan cuenta que las brechas más relevantes se

${ }^{16}$ La denominación "bruta" hace referencia a que las brechas salariales surgen de la simple comparación de los ingresos laborales percibidos por los ocupados en cada una de las categorías comparadas, sin condicionar por características del trabajador ni del puesto. 
observan entre los AFMCT y los AINC en los 2000s y entre los AFMCT y los CPPyP en la segunda parte de la década de 1990. Por otra parte, los AFMCT registran menores brechas salariales respecto a los AFMCA y a los AIC (aunque en los últimos años se redujo considerablemente la brecha con los $\mathrm{CPPyP}$, producto, posiblemente del rol de la negociación colectiva).

Estas diferencias salariales no pueden ser consideradas como evidencia de segmentación porque no surgen de la comparación de individuos "iguales" en todos los aspectos excepto del salario que perciben y porque además la decisión del puesto de trabajo al que acceden los trabajadores puede no ser exógena.

Para abordar posibles problemas de endogeneidad se implementa una estrategia adicional de estimación. La misma consiste en computar los diferenciales salariales asociadas con las transiciones desde un tipo de inserción laboral a otro que indican el incremento o disminución porcentual en el ingreso del trabajador como resultado de esa transición ${ }^{17}$. Es decir, para cada uno de los ocupados que se desplazaron desde un segmento laboral a otro, se computa la diferencia porcentual entre el ingreso que obtenía en la categoría inicial con el que percibe en la categoría final. La ventaja de este método con relación a la estimación de brechas salariales brutas entre los ocupados en los distintos segmentos es que no surgen de comparar trabajadores con distintas características productivas que podrían explicar en gran medida los diferenciales salariales observados, puesto que se compara el ingreso que el mismo ocupado obtenía en un segmento con el que percibe en otro, luego de moverse desde el primero al segundo. Asimismo, se controlan las características observables ${ }^{18}$ e inobservables ${ }^{19}$ de los trabajadores con un modelo de panel con efectos fijos $(\mathrm{EF})^{20}$.

17 Uno de los problemas de esta estrategia es la reducción del número de observaciones.

18 Sexo, experiencia potencial, educación, posición en el hogar y características del puesto de trabajo como calificación de la tarea que requiere, horas trabajadas, sector de actividad (público o privado), tamaño del establecimiento, rama de actividad y antigüedad laboral en el puesto.

19 Por ejemplo, factores inobservables invariantes en el tiempo como la habilidad de los trabajadores.

20 No obstante, existen una serie de limitaciones asociadas a la estimación de las brechas salariales mediante efectos fijos (EF). Por un lado, el método de EF no controla por ciertas variables omitidas inobservables que varían en el tiempo ni, principalmente, por ciertos beneficios no pecuniarios asociados al puesto que pueden influir en la decisión voluntaria sobre en qué segmento desempeñarse. A pesar de ello, es posible que esas características inobservables variantes en el tiempo así como los beneficios no pecuniarios no produzcan un sesgo significativo en las brechas salariales estimadas considerando que la características inobservables que varían en el tiempo no son numerosas y que los efectos de 
Los resultados de la estimación por EF muestran la existencia de una brecha positiva y significa entre empleos asalariados formales e informales. Por otra parte, cuando las comparaciones se realizan considerando los ingresos laborales de los empleados formales estables a tiempo completo o a tiempo parcial voluntario, las brechas salariales entre estos puestos formales y los informales se amplían levemente. En cambio, cuando la categoría de comparación es la de los asalariados formales en empleos atípicos (a plazo definido o part time involuntario), las brechas de ingreso con los asalariados informales son menores, pero significativas (con excepción del periodo 1995-1996). Además, si las comparaciones se realizan con el ingreso laboral de los asalariados informales calificados, las brechas salariales con los empleados formales, cualquiera sea su modalidad de contratación, son menores que las obtenidas considerando el salario percibido por los asalariados informales no calificados. Aunque, estas diferencias sólo resultan estadísticamente significativas en los 2000s.

Los resultados obtenidos no avalan la existencia de segmentación dentro del empleo asalariado formal y dentro del empleo asalariado informal (con excepción del periodo 1995/96 en el primer caso y 2005/06 en el segundo caso). Es decir, no se observa una brecha de ingresos significativa entre las categorías AFMCT y AFMCA y entre AIC y AINC. A su vez, dentro del segmento de empleo formal, no se aprecia una brecha significativamente diferente de cero entre el sector privado y el público.

Dentro del empleo independiente, se constata una brecha salarial estadísticamente significativa entre los CPPyP y los CPOyS. Además, las comparaciones de los ingresos laborales de los CPOyS con el percibido por los asalariados formales con similares características, tanto en modalidades típicas como atípicas, muestran brechas negativas y significativas (salvo en el período 1995/96). Estos resultados sugieren que los cuenta propias de oficio y subsistencia parecen presentar dificultades para acceder a un trabajo asalariado formal en el que, dadas sus características, obtendrían un mayor ingreso.

las variables inobservables asociadas a los beneficios no pecuniarios que no varían en el tiempo son eliminados mediante el método EF. Por otra parte, como las brechas se computan entre ocupados en distintas categorías laborales podrían estar capturando un potencial sesgo de selección dentro del empleo. Para evaluar el impacto de este sesgo de selección muestral, se implementó un método de corrección de las estimaciones por este problema. En el Anexo 2 se presentan las brechas estimadas con el método de FE considerando distintas especificaciones del modelo sin y con variables de control así como sin y con corrección por sesgo de selección dentro del empleo. En el Anexo 3 se describe la metodología utilizada. Para más detalles sobre este tipo de estimación consultar: Heckman (1979), Vella (1998) y Wooldridge (1995). 
Por otra parte, se aprecian diferenciales de ingresos negativos y significativos con los CPOyS y los $\mathrm{AIC}^{21}$. Estos resultados podrían indicar la existencia de segmentación dentro del segmento informal, pero no entre asalariados informales calificados y no calificados sino entre asalariados informales y cuenta propias informales.

\section{Gráfico 8. Brechas salariales condicionadas asociadas a las} transiciones entre categorías laborales, estimadas con el método de FE. Resultados estadísticamente diferentes de cero

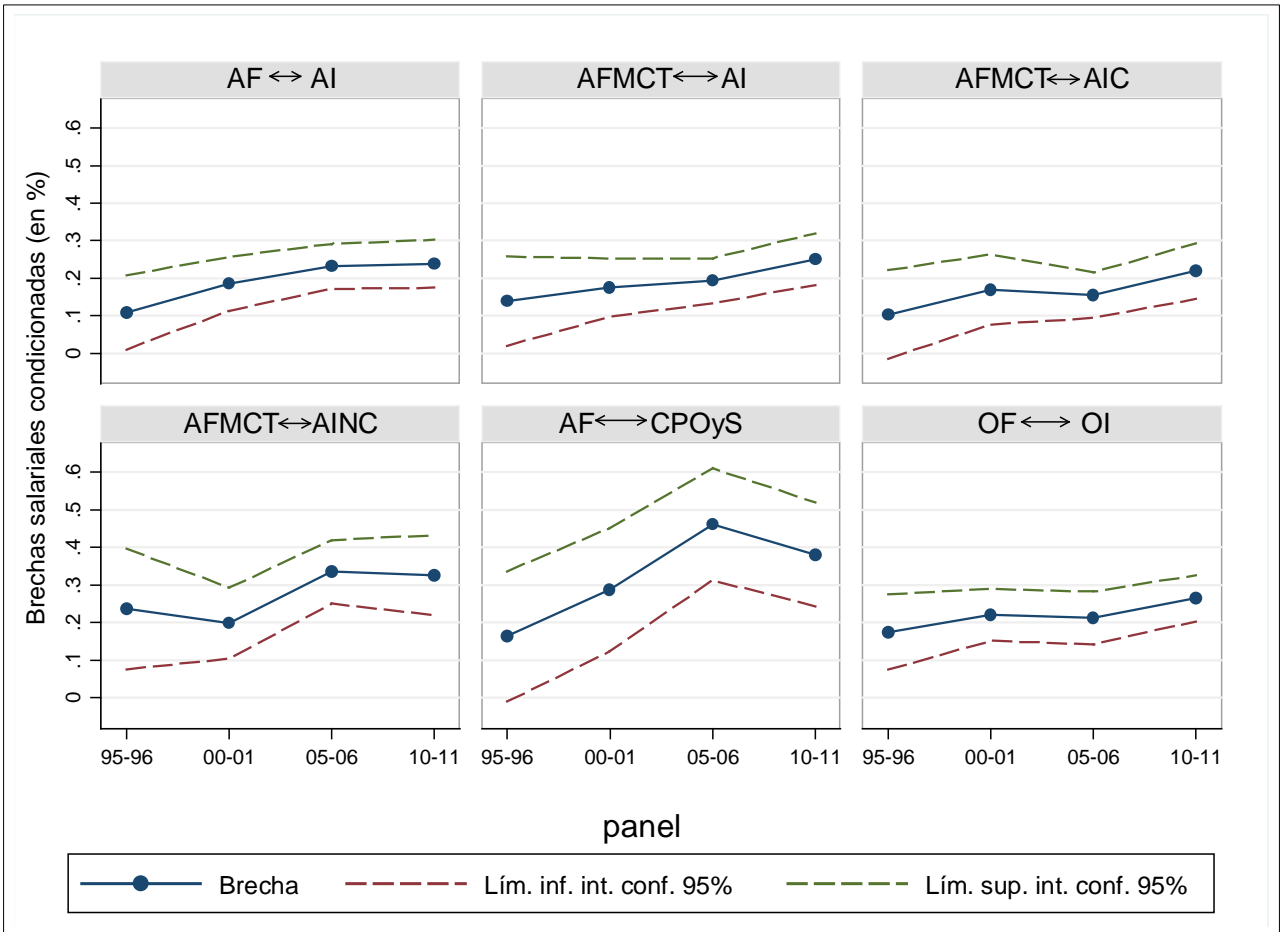

Nota: $\leftrightarrow$ : denota transiciones o trayectorias entre categorías laborales. Solo se presentan los resultados estadísticamente significativos en los cuatro paneles considerados (para mayor detalle ver Anexo 2). OF hace referencia a los ocupados formales, es decir a los AF, los CPPyP y al resto de cuenta propias que se desempeñan en establecimientos del sector público o con más de 5 trabajadores. OI corresponde a los ocupados informales, es decir el resto de las inserciones laborales.

Fuente: elaboración propia sobre la base de datos de la EPH-INDEC.

21 Cabe destacar que la dirección y magnitud de las brechas salariales estimadas con el método de FE entre las distintas categorías laborales consideradas no se modifican significativamente cuando son corregidas por un potencial sesgo de selección muestral dentro del empleo (ver Anexo 2). 


\section{Reflexiones finales y conclusiones}

Este documento presenta algunos contrastes registrados en el desempeño del mercado de trabajo de Argentina en lo que refiere a calidad -del empleo y segmentación laboral entre la década de 1990 y los 2000s.

En cuanto a la generación de empleo, se observa que durante los 90s la tasa de empleo exhibió grandes ciclos y en particular la participación del empleo asalariado registrado (típico y atípico) registró una tendencia decreciente aun cuando se desarrollaron políticas de flexibilización laboral y de reducción de contribuciones patronales a la seguridad social que en principio suponían que tendrían un impacto positivo en el empleo formal. Con la flexibilización laboral de 1995, el (bajo) crecimiento del empleo que acompañó a la fase expansiva del producto se explica en casi un 60\% por empleos atípicos (duración determinada y personal de agencia). Pero por otra parte, se aprecia una importante reducción del empleo bajo este tipo de modalidad durante el periodo de recesión y crisis de la Convertibilidad, aun cuando las modalidades promovidas habían sido derogadas a mediados de 1998.

Por otra parte, si bien las modalidades contractuales promovidas explican una parte importante de la creación/destrucción de empleo en la década de 1990, estas modalidades de empleos atípicos no llegaron a tener un peso como el que éstas tienen en algunos países de Europa. Esto puede deberse, en parte, a la "flexibilización de facto" que puede existir en un mercado de trabajo con elevados índices de informalidad laboral (tanto en el empleo asalariado como en el empleo independiente).

Durante los 2000s se verifica un aumento del empleo, y en particular del empleo asalariado formal. Esto se registra en un contexto donde se dio marcha atrás con las reformas flexibilizadoras de la década anterior (tanto en lo que refiere a la legislación de protección del empleo como a las reducciones generales de contribuciones patronales). Este resultado, por lo tanto, permite rechazar la hipótesis que sostiene que la desregulación y la mayor flexibilización laboral y de reducción de costos laborales conducen concluyentemente a un menor nivel de informalidad. Por el contrario, la evidencia pone de manifiesto la importancia de la configuración macroeconómica y de otras políticas que fomentan la creación de trabajo decente.

Además, durante los 2000s se aprecia una disminución del empleo independiente, en particular el de subsistencia. De este modo, no se verifica el hecho estilizado que vincula al endurecimiento de la regulación 
laboral (en este caso, la eliminación de las modalidades contractuales a plazo) con una mayor proporción de empleo independiente. Por lo contrario, se observa una reducción de este tipo de empleo junto con el mencionado incremento del empleo asalariado formal típico.

En cuanto a la rotación y movilidad laboral, se constata que en los 2000s disminuyó la rotación laboral de los asalariados formales con modalidades contractuales típicas. Asimismo, entre los trabajadores informales también se aprecia una menor rotación laboral en los 2000s, particularmente entre los no calificados.

Las transiciones estimadas dan cuenta de una elevada movilidad, no solo en los segmentos con niveles elevados de informalidad sino también en el segmento de mayor formalidad. Esto a priori contrasta con el supuesto de baja movilidad de la teoría de mercados laborales segmentados. No obstante, como se mencionó anteriormente, las tasas de entrada y salida son considerablemente menores en el segmento de empleo asalariado formal con modalidad típica pero se observa que el mayor flujo de nuevos puestos asalariados formales (típicos y atípicos) proviene del empleo asalariado informal calificado.

El porcentaje de trabajadores que transita entre empleos asalariados formales típicos e informales es relativamente importante, pudiendo poner en duda la relevancia de las barreras para el acceso a un empleo formal. Esto último podría considerarse como un argumento a favor de la visión de escape de la formalidad (la informalidad como un fenómeno voluntario). Sin embargo, se encontró evidencia sobre la existencia de un diferencial salarial entre estos tipos de empleo. Asimismo, otros estudios realizados para Argentina muestran que los asalariados informales no deciden sobre su condición de formalidad/informalidad (Banco Mundial y MTEySS, 2008; Bertranou et al., 2011), y destacan que un porcentaje elevado de ellos se desempeña en unidades productivas formales (Banco Mundial y MTEySS, 2008; Bertranou et al., 2011). Esto último podría vincularse con la hipótesis estructuralista del fenómeno de informalidad en Argentina en el sentido de los vínculos que pueden existir entre el sector formal e informal (Chen, 2007; Portes et al. 1989).

Por otra parte, se encontró evidencia de segmentación (a partir de las brechas salariales condicionadas) y menor movilidad laboral entre el empleo independiente y el empleo asalariado formal. Esto estaría en línea con otros estudios que encuentran para los trabajadores independientes informales un fenómeno de doble exclusión, ya que, por un lado, quedan excluidos del sector formal de la economía y, por otro lado, también quedan excluidos del trabajo asalariado (Contartese et al., 2011). No 
obstante, este tipo de fenómeno de doble exclusión no puede extenderse al total del empleo independiente ya para otros grupos (minoritarios) de trabajadores independientes este tipo de inserción laboral es preferida al empleo asalariado (Banco Mundial y MTEySS, 2008).

Finalmente, los resultados del análisis de segmentación laboral a partir de la estimación de brechas salariales condicionadas, utilizando el método de EF, sugieren la existencia de una estructura segmentada en el mercado laboral de la Argentina pero principalmente asociada al fenómeno de la informalidad de los trabajadores. En efecto, el hallazgo más robusto obtenido del análisis de las brechas de ingresos es la existencia de un premio salarial asociado con los puestos asalariados formales en comparación con los informales. En cambio, los resultados no parecen confirmar la hipótesis de segmentación de los empleados según modalidad de contratación al interior del empleo asalariado formal ni al interior del empleo asalariado informal; excepto entre el empleo asalariado informal y los cuenta propias de oficio y subsistencia.

De este modo, la evidencia presentada da cuenta que el fenómeno más extendido que afecta la calidad del empleo es la informalidad laboral. El abordaje empírico de este documento, así como el de otros estudios realizados, destaca que la informalidad en Argentina no se encuentra asociada a una única causa en particular (asociada al escape o a la exclusión, sea esta última considerada desde una visión dualista o estructural) si no que pueden ser varios los factores que determinan el nivel y las características del empleo informal.

\section{Bibliografía}

Alzúa, M. L. (2008). "Are Informal Workers Secondary Workers?: Evidence for Argentina", Documento de Trabajo $N^{\circ}$ 73. CEDLAS. Universidad Nacional de La Plata.

Arias, O. y Khamis, M. (2008). "Comparative Advantage, Segmentation and Informal Earnings: A Marginal Treatment Effects Approach", Institute for the Study of Labor (IZA), Discussion Paper № 3916.

Banco Mundial y MTEySS, (2008), Aportes a una nueva visión de la informalidad laboral en la Argentina, Banco Mundial y Ministerio de Trabajo, Empleo y Seguridad Social. Buenos Aires.

Beccaria, L., Groisman, F. y Monsalvo, P. (2007). "Informalidad y 
pobreza en Argentina", Anales de la Asociación Argentina de Economía Política, Buenos Aires.

Benítez, N., Contartese, D., Mazorra, X., Schachtel, L. y D. Scheleser (2011), "La inserción laboral de la población desde una perspectiva dinámica", en MTEySS, Serie Estudios/10 Trabajo, ocupación y Empleo. La complejidad del empleo, la protección social y las relaciones laborales. Diciembre, Buenos Aires.

Bertranou, F. y R. Maurizio (eds) (2011), Trabajadores independientes, mercado laboral e informalidad en Argentina, Oficina Internacional del Trabajo. Buenos Aires.

Bertranou, F., Casanova, L. y M. Sarabia, (2013a), "Dónde, cómo y por qué se redujo la informalidad laboral en Argentina durante el período 2003-2012", Documento en progreso, Oficina Internacional del Trabajo. Buenos Aires.

Bertranou, F., Casanova, L., Jiménez, M y M. Jiménez, (2013b), "Informalidad, calidad del empleo y segmentación laboral", Documento de Trabajo No.2, Oficina Internacional del Trabajo. Buenos Aires.

Bertranou, F., R. Mercau, S. Jardel y R. González (2011), Informalidad laboral en la provincia de Mendoza: características y políticas para promover la formalización, Oficina Internacional del Trabajo, Buenos Aires.

Cazes, S. y Tonin, M., (2009), "Employment Protection Legislation and Job Stability: An European Cross Country Analysis", Discussion Papers in Economics and Econometrics $\mathrm{N}^{\circ}$ 0902, School of Social Sciences, Economics Division, University of Southampton.

Chen, M., (2007), "Rethinking the informal economy: linkages with the formal economy and the formal regulatory environment", DESA Working Paper $\mathrm{N}^{\circ} 46$.

Contartese, D., Mazorra, X., Schachtel, L. y D. Scheleser (2011), "La informalidad en el trabajo independiente: ¿escape o exclusión?", en Bertranou, F. y Maurizio, R. (eds.), Trabajadores independientes, mercado laboral e informalidad en Argentina, OIT Argentina, Buenos Aires.

Damill, M., Frenkel, R., Maurizio, R., (2011), Macroeconomic policy for full and productive employment and decent work for all. An analysis of the Argentine experience, Oficina Internacional del Trabajo. Ginebra. 
EU, (2010), "Self-employment in Europe. 2010", European Employment Observatory Review, European Union. Luxemburg.

Fields, G., (1990), "Labour market modeling and urban informal sector", en D. Turnham, B. Salomé, A., Schwarz (Eds.), The informal sector revisited, OECD. París.

Fields, G., (2009), "Segmented labor market models in developing countries", en H. Kincaid and D. Ross (Eds.) The Oxford handbook of philosophy of economics, pp. 476-510. Oxford: Oxford University Press.

Fundación SOL (2012), Minuta de empleo $N^{\circ}$ 9. Diciembre - Febrero, Fundación SOL, Santiago.

Galli, R., Kucera, D., (2004), Labor Standards and Informal Employment in Latin America, World Development 32(5), 809-828.

Gasparini, L., (2000), "La informalidad laboral en Argentina: evolución y caracterización", en La economía oculta en la Argentina, FIEL, Buenos Aires.

Hausman, J. A. (1978), "Specification Tests in Econometrics," Econometrica, 46, 1251-1271.

Heckman, J. (1979), "Sample selection as a specification error" Econometrica, 47, pp. 153-61.

Heckman, J., y Pagés, C., (2005), "Introducción”, en J. Heckman and C. Pagés (Eds.), Regulación y empleo: Lecciones de América Latina y el Caribe, CIEDESS, Santiago.

Heston, A., Summers, R., Aten, B., (2012), Penn World Table Version 7.1, Center for International Comparisons of Production, Income and Prices at the University of Pennsylvania, July 2012. Pennsylvania.

Jiménez, M., (2011), "La Economía Informal y el Mercado Laboral en la Argentina: Un Análisis desde la Perspectiva del Trabajo Decente", Documento de trabajo $N^{\circ} 116$, CEDLAS, Universidad Nacional de La Plata. La Plata.

Maloney, W., (1999), "Does informality imply segmentation in urban labour markets? Evidence from sectoral transitions in Mexico", The World Bank Economic Review Vol 13, N² 2, pags. 275-302, World Bank. Washington D.C.

MTEySS (2010), Trabajo y Empleo en el Bicentenario: Cambio en la Dinámica del Empleo y la Protección Social para la Inclusión, 
Ministerio de Trabajo, Empleo y Seguridad Social. Buenos Aires.

MTEySS y OIT (2012), Macroeconomía, empleo e ingresos: debates y politicas en Argentina frente a la crisis internacional 2008-2009, Oficina de País de la OIT para la Argentina. Buenos Aires.

OIT. (2002). "El Trabajo Decente y la Economía Informal”, 90 Conferencia Internacional del Trabajo, Ginebra.

OIT, (2009), Informe nacional sobre el impacto social de la globalización en Argentina, Oficina Internacional el Trabajo. Buenos Aires.

OIT, (2011a), Statistical update on employment in the informal economy, International Labour Office. Geneva.

OIT, (2011b), Panorama Laboral 2011. América Latina y el Caribe, Oficina Internacional del Trabajo. Lima.

OIT (2012), World of Work Report 2012. Better Jobs for a Better Economy, Geneva, International Labour Office.

Paz, J. (2013), "Segmentación del mercado de trabajo en la Argentina", Revista Desarrollo y Sociedad ํㅜ 72, pp. 105-156.

Portes, A., Castells, M., Benton, L., (eds.), (1989), The Informal Economy, Baltimore, Md.: Johns Hopkins University Press.

Pratap, S. y Quintín, E. (2006). "Are Labour Markets Segmented in Developing Countries? A Semiparametric Approach”, European Economic Review No 50, pp. 507-542.

Ranis, G., Stewart, F., (1999), "V-Goods and the Role of the Urban Informal Sector in Development", Economic Development and Cultural Change, Vol. 47, No. 2, pp. 259-288.

Rodgers, G., (1989), "Precarious work in Western Europe: the state of the debate", in G. Rodgers and J. Rodgers (eds), Precarious jobs in labour market regulation: the growth of atypical employment in Western Europe, International Labour Organization. Geneva.

Taubman, P., y M., Wachter, (1986), "Segmented labor markets", en O. Ashenfelter y R. Layard (eds.), Handbook of Labor Economics, Vol. N ${ }^{\circ}$ 2, pp. 1183-1217.

Tokman, V. (dr.) (2001), De la informalidad a la modernidad, Oficina Internacional del Trabajo. Santiago de Chile.

Urrea, F., (2011), "Dinámica de reestructuración productiva, cambios institucionales y políticos y procesos de desregulación de las relaciones 
asalariadas: el caso colombiano", en De La Garza, E., y Neffa, J., Trabajo y modelos productivos en América Latina. CLACSO. Buenos Aires.

Vella, F. (1998). "Estimating models with sample selection bias: A survey", Journal of Human Resources, 3, pp. 127-69.

Wooldridge, J. M. (1995), "Selection Corrections for Panel Data Models under Conditional Mean Independence Assumptions," Journal of Econometrics 68, pp. 115-132. 


\section{Anexo 1. Trayectorias laborales, 1995-2011}

\begin{tabular}{|c|c|c|c|c|c|c|c|c|c|c|}
\hline \multicolumn{11}{|c|}{ Probabilidad de desplazarse desde una categoría inicial hacia una terminal } \\
\hline \multirow{2}{*}{\multicolumn{2}{|c|}{$\begin{array}{l}\text { Estado en el período } \\
\text { inicial/Estado en el período } \\
\text { final }\end{array}$}} & \multirow{2}{*}{ Inactivo } & \multirow{2}{*}{ Desocupado } & \multicolumn{3}{|c|}{ Independientes } & \multicolumn{2}{|c|}{ Asalariado informal } & \multicolumn{2}{|c|}{$\begin{array}{c}\text { Asalariado } \\
\text { formal }\end{array}$} \\
\hline & & & & \multirow{2}{*}{ Profesional } & \multirow{2}{*}{ Oficio } & \multirow{2}{*}{$\begin{array}{c}\text { Subsistencia } \\
\mathbf{1 9 9 5 - 1 9 9 6}\end{array}$} & \multirow[t]{2}{*}{ Calificado } & \multirow[t]{2}{*}{$\begin{array}{c}\text { No } \\
\text { calificado }\end{array}$} & \multirow[t]{2}{*}{$M C T^{1}$} & \multirow[t]{2}{*}{$M C A^{2}$} \\
\hline & & & & & & & & & & \\
\hline Inactivo & & 91,29 & 4,00 & 0,15 & 0,72 & 0,56 & 0,92 & 1,54 & 0,60 & 0,23 \\
\hline Desocupado & & 27,16 & 33,64 & 0,30 & 6,82 & 2,23 & 9,99 & 10,81 & 6,55 & 2,50 \\
\hline \multirow[t]{3}{*}{ Independientes } & Profesional & 6,64 & 2,16 & 52,13 & 21,28 & 5,92 & 8,02 & 0,31 & 3,15 & 0,39 \\
\hline & Oficio & 10,01 & 11,94 & 7,38 & 48,10 & 3,00 & 10,59 & 3,05 & 5,25 & 0,68 \\
\hline & Subsistencia & 18,50 & 8,22 & 5,92 & 9,86 & 41,91 & 3,89 & 6,97 & 3,48 & 1,25 \\
\hline \multirow{2}{*}{$\begin{array}{l}\text { Asalariado } \\
\text { informal }\end{array}$} & Calificado & 8,50 & 11,26 & 3,06 & 11,08 & 2,29 & 35,22 & 7,64 & 16,95 & 4,00 \\
\hline & $\begin{array}{l}\text { No } \\
\text { calificado }\end{array}$ & 17,52 & 14,58 & 1,30 & 4,02 & 3,81 & 8,77 & 39,46 & 9,00 & 1,55 \\
\hline \multirow[t]{2}{*}{ Asalariado formal } & $M C T^{1}$ & 2,78 & 3,84 & 1,20 & 1,71 & 0,66 & 4,37 & 1,93 & 77,61 & 5,90 \\
\hline & $M C A^{2}$ & 5,63 & 6,60 & 0,69 & 1,33 & 2,15 & 5,35 & 1,02 & 45,06 & 32,16 \\
\hline \multirow[t]{2}{*}{ Total } & & 60,66 & 7,18 & 1,71 & 4,43 & 1,96 & 4,33 & 4,07 & 13,65 & 2,04 \\
\hline & & \multicolumn{9}{|c|}{ 2001-2002 } \\
\hline Inactivo & & 91,11 & 3,80 & 0,07 & 0,85 & 0,56 & 0,90 & 1,85 & 0,68 & 0,18 \\
\hline Desocupado & & 26,18 & 38,32 & 0,53 & 9,93 & 3,50 & 6,26 & 7,90 & 5,36 & 2,02 \\
\hline \multirow{3}{*}{ Independientes } & Profesional & 8,93 & 3,45 & 55,07 & 15,43 & 6,81 & 5,04 & 0,52 & 4,55 & 0,19 \\
\hline & Oficio & 12,68 & 14,74 & 5,84 & 45,28 & 4,12 & 9,33 & 3,75 & 3,08 & 1,16 \\
\hline & Subsistencia & 17,79 & 8,94 & 4,22 & 10,66 & 44,64 & 3,10 & 9,32 & 1,22 & 0,10 \\
\hline Asalariado & Calificado & 10,39 & 14,48 & 1,00 & 10,45 & 2,03 & 37,21 & 8,02 & 13,31 & 3,11 \\
\hline & $\begin{array}{l}\text { No } \\
\text { calificado }\end{array}$ & 18,50 & 14,99 & 0,29 & 3,15 & 3,90 & 9,94 & 41,03 & 6,39 & 1,81 \\
\hline Asalariado formal & $M C T^{1}$ & 3,13 & 6,29 & 0,78 & 1,42 & 0,43 & 5,56 & 1,63 & 74,44 & 6,32 \\
\hline & $M C A^{2}$ & 3,63 & 6,91 & 0,00 & 1,46 & 0,35 & 6,31 & 2,01 & 46,90 & 32,42 \\
\hline Total & & 60,21 & 7,85 & 1,58 & 4,58 & 2,10 & 4,59 & 4,52 & 12,65 & 1,91 \\
\hline & & & & & & 2005-2006 & & & & \\
\hline Inactivo & & 85,54 & 4,32 & 0,23 & 2,25 & 0,30 & 2,58 & 3,59 & 0,92 & 0,27 \\
\hline Desocupado & & 27,38 & 25,90 & 0,71 & 9,76 & 0,82 & 11,78 & 14,35 & 7,68 & 1,62 \\
\hline Independientes & Profesional & 4,04 & 1,64 & 54,56 & 21,58 & 1,16 & 8,35 & 1,13 & 6,50 & 1,03 \\
\hline & Oficio & 13,33 & 5,63 & 5,62 & 55,09 & 2,76 & 9,12 & 5,24 & 2,44 & 0,77 \\
\hline & Subsistencia & 8,22 & 3,15 & 1,83 & 25,72 & 38,25 & 3,25 & 14,08 & 4,79 & 0,70 \\
\hline Asalariado & Calificado & 10,50 & 3,85 & 2,13 & 9,48 & 1,06 & 43,92 & 11,09 & 15,83 & 2,13 \\
\hline informal & $\begin{array}{l}\text { No } \\
\text { calificado }\end{array}$ & 17,63 & 8,01 & 0,33 & 6,09 & 1,68 & 11,06 & 47,60 & 5,83 & 1,78 \\
\hline Asalariado formal & $M C T 1$ & 2,28 & 1,88 & 1,23 & 1,35 & 0,06 & 4,56 & 1,07 & 84,56 & 3,01 \\
\hline & $M C A^{2}$ & 2,15 & 5,49 & 0,86 & 1,79 & 0,56 & 4,28 & 3,96 & 61,78 & 19,13 \\
\hline Total & & 46,94 & 5,68 & 2,46 & 8,67 & 0,97 & 8,38 & 8,21 & 17,29 & 1,40 \\
\hline & & & & & & $2010-2011$ & & & & \\
\hline Inactivo & & 86,95 & 3,19 & 0,26 & 2,24 & 0,18 & 2,34 & 3,15 & 1,45 & 0,25 \\
\hline Desocupado & & 34,10 & 20,91 & 0,88 & 8,74 & 0,61 & 11,46 & 12,09 & 9,70 & 1,51 \\
\hline Independientes & Profesional & 6,81 & 1,34 & 58,29 & 18,92 & 0,21 & 5,92 & 0,57 & 7,85 & 0,07 \\
\hline & Oficio & 15,29 & 3,94 & 7,89 & 53,75 & 1,25 & 7,80 & 4,97 & 4,41 & 0,70 \\
\hline & Subsistencia & 14,58 & 0,19 & 1,30 & 20,93 & 39,64 & 8,85 & 12,39 & 0,97 & 1,15 \\
\hline Asalariado & Calificado & 12,66 & 7,00 & 2,96 & 11,76 & 0,09 & 37,66 & 8,82 & 16,44 & 2,61 \\
\hline informal & $\begin{array}{l}\text { No } \\
\text { calificado }\end{array}$ & 18,72 & 6,84 & 0,95 & 5,74 & 0,82 & 13,28 & 43,51 & 8,26 & 1,88 \\
\hline Asalariado formal & MCT1 & 3,61 & 1,56 & 1,10 & 1,53 & 0,03 & 3,52 & 1,56 & 84,67 & 2,43 \\
\hline & $M C A^{2}$ & 6,62 & 3,09 & 1,07 & 1,79 & 0,26 & 6,39 & 8,20 & 53,67 & 18,90 \\
\hline Total & & 48,87 & 4,10 & 3,16 & 8,08 & 0,49 & 6,68 & 6,32 & 21,01 & 1,29 \\
\hline
\end{tabular}

Notas: (1) MCNA: modalidad contractual no atípica. (2) MCT: modalidad contractual típica. Los valores presentados en la fila "Total" representan la proporción de individuos en cada categoría al final de cada periodo.

Fuente: elaboración propia sobre la base de datos de la EPH-INDEC.

\section{Cont.}


60 Bertranou et al /Revista de Economía Laboral 11 (2014), 24-64

\begin{tabular}{|c|c|c|c|c|c|c|c|c|c|c|}
\hline \multicolumn{11}{|c|}{ Probabilidad de transición estandarizada por tamaño de sector terminal } \\
\hline \multirow{2}{*}{\multicolumn{2}{|c|}{$\begin{array}{l}\text { Estado en el período } \\
\text { inicial/Estado en el período final }\end{array}$}} & \multirow{2}{*}{ Inactivo } & \multirow{2}{*}{ Desocupado } & \multicolumn{3}{|c|}{ Independientes } & \multicolumn{2}{|c|}{ Asalariado informal } & \multicolumn{2}{|c|}{$\begin{array}{c}\text { Asalariado } \\
\text { formal }\end{array}$} \\
\hline & & & & \multirow[t]{2}{*}{ Profesional } & \multirow[t]{2}{*}{ Oficio } & \multirow{2}{*}{$\begin{array}{c}\text { Subsistencia } \\
1995-1996\end{array}$} & \multirow[t]{2}{*}{ Calificado } & \multirow[t]{2}{*}{$\begin{array}{c}\text { No } \\
\text { calificado }\end{array}$} & \multirow[t]{2}{*}{$M C T^{1}$} & \multirow[t]{2}{*}{$M C A^{2}$} \\
\hline & & & & & & & & & & \\
\hline Inactivo & & & 55,71 & 8,77 & 16,25 & 28,57 & 21,25 & 37,84 & 4,40 & 11,27 \\
\hline Desocupado & & 44,77 & & 17,54 & 153,95 & 113,78 & 230,72 & 265,60 & 47,99 & 122,55 \\
\hline \multirow[t]{3}{*}{ Independientes } & Profesional & 10,95 & 30,08 & & 480,36 & 302,04 & 185,22 & 7,62 & 23,08 & 19,12 \\
\hline & Oficio & 16,50 & 166,30 & 431,58 & & 153,06 & 244,57 & 74,94 & 38,46 & 33,33 \\
\hline & Subsistencia & 30,50 & 114,48 & 346,20 & 222,57 & & 89,84 & 171,25 & 25,49 & 61,27 \\
\hline \multirow[t]{2}{*}{ Asalariado informal } & Calificado & 14,01 & 156,82 & 178,95 & 250,11 & 116,84 & & 187,71 & 124,18 & 196,08 \\
\hline & No calificado & 28,88 & 203,06 & 76,02 & 90,74 & 194,39 & 202,54 & & 65,93 & 75,98 \\
\hline \multirow[t]{2}{*}{ Asalariado formal } & $\mathrm{MCT}^{1}$ & 4,58 & 53,48 & 70,18 & 38,60 & 33,67 & 100,92 & 47,42 & & 289,22 \\
\hline & $\mathrm{MCA}^{2}$ & 9,28 & 91,92 & 40,35 & 30,02 & 109,69 & 123,56 & 25,06 & 330,11 & \\
\hline & & \multicolumn{9}{|c|}{$2000-2001$} \\
\hline Inactivo & & & 48,41 & 4,43 & 18,56 & 26,67 & 19,61 & 40,93 & 5,38 & 9,42 \\
\hline Desocupado & & 43,48 & & 33,54 & 216,81 & 166,67 & 136,38 & 174,78 & 42,37 & 105,76 \\
\hline \multirow[t]{3}{*}{ Independientes } & Profesional & 14,83 & 43,95 & & 336,90 & 324,29 & 109,80 & 11,50 & 35,97 & 9,95 \\
\hline & Oficio & 21,06 & 187,77 & 369,62 & & 196,19 & 203,27 & 82,96 & 24,35 & 60,73 \\
\hline & Subsistencia & 29,55 & 113,89 & 267,09 & 232,75 & & 67,54 & 206,19 & 9,64 & 5,24 \\
\hline \multirow{2}{*}{ Asalariado informal } & Calificado & 17,26 & 184,46 & 63,29 & 228,17 & 96,67 & & 177,43 & 105,22 & 162,83 \\
\hline & No calificado & 30,73 & 190,96 & 18,35 & 68,78 & 185,71 & 216,56 & & 50,51 & 94,76 \\
\hline \multirow[t]{2}{*}{ Asalariado formal } & $\mathrm{MCT}^{1}$ & 5,20 & 80,13 & 49,37 & 31,00 & 20,48 & 121,13 & 36,06 & & 330,89 \\
\hline & $\mathrm{MCA}^{2}$ & 6,03 & 88,03 & 0,00 & 31,88 & 16,67 & 137,47 & 44,47 & 370,75 & \\
\hline & & \multicolumn{9}{|c|}{$2005-2006$} \\
\hline Inactivo & & & 76,06 & 9,35 & 25,95 & 30,93 & 30,79 & 43,73 & 5,32 & 19,29 \\
\hline Desocupado & & 58,33 & & 28,86 & 112,57 & 84,54 & 140,57 & 174,79 & 44,42 & 115,71 \\
\hline Independientes & Profesional & 8,61 & 28,87 & & 248,90 & 119,59 & 99,64 & 13,76 & 37,59 & 73,57 \\
\hline & Oficio & 28,40 & 99,12 & 228,46 & & 284,54 & 108,83 & 63,82 & 14,11 & 55,00 \\
\hline & Subsistencia & 17,51 & 55,46 & 74,39 & 296,66 & & 38,78 & 171,50 & 27,70 & 50,00 \\
\hline Asalariado informal & Calificado & 22,37 & 67,78 & 86,59 & 109,34 & 109,28 & & 135,08 & 91,56 & 152,14 \\
\hline & No calificado & 37,56 & 141,02 & 13,41 & 70,24 & 173,20 & 131,98 & & 33,72 & 127,14 \\
\hline Asalariado formal & $\mathrm{MCT}^{1}$ & 4,86 & 33,10 & 50,00 & 15,57 & 6,19 & 54,42 & 13,03 & & 215,00 \\
\hline & $\mathrm{MCA}^{2}$ & 4,58 & 96,65 & 34,96 & 20,65 & 57,73 & 51,07 & 48,23 & 357,32 & \\
\hline & & & & & & $2010-2011$ & & & & \\
\hline Inactivo & & & 77,80 & 8,23 & 27,72 & 36,73 & 35,03 & 49,84 & 6,90 & 19,38 \\
\hline Desocupado & & 69,78 & & 27,85 & 108,17 & 124,49 & 171,56 & 191,30 & 46,17 & 117,05 \\
\hline Independientes & Profesional & 13,93 & 32,68 & & 234,16 & 42,86 & 88,62 & 9,02 & 37,36 & 5,43 \\
\hline & Oficio & 31,29 & 96,10 & 249,68 & & 255,10 & 116,77 & 78,64 & 20,99 & 54,26 \\
\hline & Subsistencia & 29,83 & 4,63 & 41,14 & 259,03 & & 132,49 & 196,04 & 4,62 & 89,15 \\
\hline Asalariado informal & Calificado & 25,91 & 170,73 & 93,67 & 145,54 & 18,37 & & 139,56 & 78,25 & 202,33 \\
\hline & No calificado & 38,31 & 166,83 & 30,06 & 71,04 & 167,35 & 198,80 & & 39,31 & 145,74 \\
\hline Asalariado formal & $\mathrm{MCT}^{1}$ & 7,39 & 38,05 & 34,81 & 18,94 & 6,12 & 52,69 & 24,68 & & 188,37 \\
\hline & $\mathrm{MCA}^{2}$ & 13,55 & 75,37 & 33,86 & 22,15 & 53,06 & 95,66 & 129,75 & 255,45 & \\
\hline
\end{tabular}

Notas: (1) MCNA: modalidad contractual no atípica. (2) MCT: modalidad contractual típica. Las probabilidades estandarizadas surgen del cociente entre las probabilidades de transición y los tamaños de los sectores o categorías laborales de destino reportados en la última fila del cuadro anterior.

Fuente: elaboración propia sobre la base de datos de la EPH. 


\section{Anexo 2. Brechas salariales estimadas a partir de modelo de datos} de panel con efectos fijos

\begin{tabular}{|c|c|c|c|c|c|c|c|c|c|c|c|c|c|c|c|c|}
\hline \multirow{3}{*}{ Transiciones } & \multicolumn{4}{|c|}{$1995-96$} & \multicolumn{4}{|c|}{$2000-01$} & \multicolumn{4}{|c|}{$2005-06$} & \multicolumn{4}{|c|}{$2010-11$} \\
\hline & \multicolumn{2}{|c|}{$\begin{array}{l}\text { Brechas sin } \\
\text { cond. }\end{array}$} & \multicolumn{2}{|c|}{ Brechas cond. } & \multicolumn{2}{|c|}{$\begin{array}{l}\text { Brechas sin } \\
\text { cond. }\end{array}$} & \multicolumn{2}{|c|}{ Brechas cond. } & \multicolumn{2}{|c|}{$\begin{array}{l}\text { Brechas sin } \\
\text { cond. }\end{array}$} & \multicolumn{2}{|c|}{ Brechas cond. } & \multicolumn{2}{|c|}{$\begin{array}{l}\text { Brechas sin } \\
\text { cond. }\end{array}$} & \multicolumn{2}{|c|}{ Brechas cond. } \\
\hline & $\begin{array}{c}\text { No } \\
\text { correg. }\end{array}$ & Correg. & $\begin{array}{c}\text { No } \\
\text { correg. }\end{array}$ & Correg. & $\begin{array}{c}\text { No } \\
\text { correg. }\end{array}$ & Correg. & $\begin{array}{c}\text { No } \\
\text { correg. }\end{array}$ & Correg. & $\begin{array}{c}\text { No } \\
\text { correg. }\end{array}$ & Correg. & $\begin{array}{c}\text { No } \\
\text { correg. }\end{array}$ & Correg. & $\begin{array}{c}\text { No } \\
\text { correg. }\end{array}$ & Correg. & $\begin{array}{c}\text { No } \\
\text { correg. }\end{array}$ & Correg. \\
\hline \multicolumn{17}{|c|}{$\begin{array}{l}\text { Entre puestos asalariados formales } \\
\text { Y puestos asalariados } \\
\text { informales }\end{array}$} \\
\hline $\mathrm{AF}$ «AI & $\begin{array}{c}10,2 \% \\
(0,040)\end{array}$ & $\begin{array}{c}10,8 \% \\
(0,042)\end{array}$ & $\begin{array}{c}10,9 \% \\
(0,050)\end{array}$ & $\begin{array}{c}10,5 \% \\
(0,050)\end{array}$ & $\begin{array}{c}20,7 \% \\
(0,033)\end{array}$ & $\begin{array}{c}19,5 \% \\
(0,032)\end{array}$ & $\begin{array}{c}18,6 \% \\
(0,037)\end{array}$ & $\begin{array}{c}19,8 \% \\
(0,036)\end{array}$ & $\begin{array}{c}29,1 \% \\
(0,030)\end{array}$ & $\begin{array}{c}27,9 \% \\
(0,029)\end{array}$ & $\begin{array}{c}23,2 \% \\
(0,031)\end{array}$ & $\begin{array}{c}22,6 \% \\
(0,030)\end{array}$ & $\begin{array}{c}29,1 \% \\
(0,036)\end{array}$ & $\begin{array}{l}28,5 \% \\
(0,034)\end{array}$ & $\begin{array}{c}23,9 \% \\
(0,033)\end{array}$ & $\begin{array}{l}24,2 \% \\
(0,032)\end{array}$ \\
\hline \multirow[t]{2}{*}{$\mathrm{AFMCT} \ll \mathrm{AI}$} & $\begin{array}{l}23.193 \\
16,3 \% \\
(0,048)\end{array}$ & $\begin{array}{l}22.174 \\
16,4 \% \\
(0,050)\end{array}$ & $\begin{array}{l}17.753 \\
13,9 \% \\
(0,061)\end{array}$ & $\begin{array}{l}18.144 \\
13,8 \% \\
(0,061)\end{array}$ & $\begin{array}{l}18.264 \\
19,4 \% \\
(0,035)\end{array}$ & $\begin{array}{l}18.104 \\
17,5 \% \\
(0,035)\end{array}$ & $\begin{array}{l}15.340 \\
17,5 \% \\
(0,040)\end{array}$ & $\begin{array}{l}15.762 \\
17,7 \% \\
(0,040)\end{array}$ & $\begin{array}{r}26.749 \\
29,5 \% \\
(0,034)\end{array}$ & $\begin{array}{l}26.695 \\
26,6 \% \\
(0,033)\end{array}$ & $\begin{array}{l}21.928 \\
19,3 \% \\
(0,031)\end{array}$ & $\begin{array}{l}23.332 \\
18,2 \% \\
(0,031)\end{array}$ & $\begin{array}{l}33.657 \\
34,6 \% \\
(0,046)\end{array}$ & $\begin{array}{l}33.599 \\
32,4 \% \\
(0,043)\end{array}$ & $\begin{array}{l}27.591 \\
25,1 \% \\
(0,035)\end{array}$ & $\begin{array}{l}29.205 \\
24,0 \% \\
(0,035)\end{array}$ \\
\hline & $\begin{array}{c}16.962 \\
4,4 \%\end{array}$ & $\begin{array}{c}16.258 \\
4,9 \%\end{array}$ & $\begin{array}{c}12.493 \\
3,9 \%\end{array}$ & 12.572 & $\begin{array}{l}13.293 \\
11,8 \%\end{array}$ & $\begin{array}{l}13.197 \\
13,3 \%\end{array}$ & $\begin{array}{l}10.885 \\
15,3 \%\end{array}$ & $\begin{array}{l}10.984 \\
14,0 \%\end{array}$ & $\begin{array}{l}18.762 \\
24,6 \%\end{array}$ & $\begin{array}{l}18.749 \\
23,5 \%\end{array}$ & $\begin{array}{l}15.404 \\
17,5 \%\end{array}$ & $\begin{array}{l}15.612 \\
16,3 \%\end{array}$ & $\begin{array}{l}23.688 \\
16,6 \%\end{array}$ & 23.676 & $\begin{array}{l}19.673 \\
17,7 \%\end{array}$ & $\begin{array}{l}19.810 \\
16,3 \%\end{array}$ \\
\hline \multirow{2}{*}{ AFMCA «AI } & $(0,052)$ & $(0,056)$ & $(0,067)$ & $(0,066)$ & $(0,042)$ & $(0,042)$ & $(0,049)$ & $(0,049)$ & $(0,041)$ & $(0,039)$ & $(0,039)$ & $(0,039)$ & $(0,059)$ & $(0,056)$ & $(0,049)$ & $(0,048)$ \\
\hline & 16.962 & 16.258 & 12.493 & 12.572 & 13.293 & 13.197 & 10.885 & 10.984 & 18.762 & 18.749 & 15.404 & 15.612 & 23.688 & 23.676 & 19.673 & 19.810 \\
\hline AFMCT « AINC & $\begin{array}{c}21,9 \% \\
(0,068)\end{array}$ & $\begin{array}{l}24,4 \% \\
(0,069)\end{array}$ & $\begin{array}{c}23,6 \% \\
(0,082)\end{array}$ & $\begin{array}{c}23,7 \% \\
(0,081)\end{array}$ & $\begin{array}{c}26,5 \% \\
(0,056)\end{array}$ & $\begin{array}{c}24,5 \% \\
(0,056)\end{array}$ & $\begin{array}{c}19,8 \% \\
(0,048)\end{array}$ & $\begin{array}{c}18,5 \% \\
(0,048)\end{array}$ & $\begin{array}{c}44,8 \% \\
(0,042)\end{array}$ & $\begin{array}{c}40,5 \% \\
(0,039)\end{array}$ & $\begin{array}{c}33,5 \% \\
(0,043)\end{array}$ & $\begin{array}{c}33,3 \% \\
(0,042)\end{array}$ & $\begin{array}{c}45,6 \% \\
(0,062)\end{array}$ & $\begin{array}{l}41,5 \% \\
(0,058)\end{array}$ & $\begin{array}{c}32,6 \% \\
(0,054)\end{array}$ & $\begin{array}{c}32,1 \% \\
(0,054)\end{array}$ \\
\hline & 16.959 & 16.255 & 12.494 & 12.573 & 13.282 & 13.186 & 10.880 & 10.979 & 18.744 & 18.732 & 15.415 & 15.623 & 23.656 & 23.645 & 19.663 & 19.800 \\
\hline $\mathrm{AFMCT}$ «AIC & $\begin{array}{c}13,8 \% \\
(0,050)\end{array}$ & $\begin{array}{c}12,9 \% \\
(0,051)\end{array}$ & $\begin{array}{c}10,3 \% \\
(0,060)\end{array}$ & $\begin{array}{c}10,2 \% \\
(0,060)\end{array}$ & $\begin{array}{r}16,4 \% \\
(0,041)\end{array}$ & $\begin{array}{l}14,6 \% \\
(0,040)\end{array}$ & $\begin{array}{c}17,0 \% \\
(0,048)\end{array}$ & $\begin{array}{l}17,8 \% \\
(0,047)\end{array}$ & $\begin{array}{r}22,0 \% \\
(0,031)\end{array}$ & $\begin{array}{l}20,2 \% \\
(0,030)\end{array}$ & $\begin{array}{c}15,5 \% \\
(0,031)\end{array}$ & $\begin{array}{c}14,1 \% \\
(0,031)\end{array}$ & $\begin{array}{c}28,6 \% \\
(0,048)\end{array}$ & $\begin{array}{l}28,0 \% \\
(0,046)\end{array}$ & $\begin{array}{r}21,9 \% \\
(0,038)\end{array}$ & $\begin{array}{l}21,2 \% \\
(0,037)\end{array}$ \\
\hline & 16.959 & 16.255 & 12.494 & 12.573 & 13.282 & 13.186 & 10.880 & 10.979 & 18.744 & 18.732 & 15.415 & 15.623 & 23.656 & 23.645 & 19.663 & 19.800 \\
\hline AFMCA«AINC & $\begin{array}{c}10,0 \% \\
(0,069)\end{array}$ & $\begin{array}{l}12,9 \% \\
(0,071)\end{array}$ & $\begin{array}{c}13,8 \% \\
(0,085)\end{array}$ & $\begin{array}{c}13,8 \% \\
(0,084)\end{array}$ & $\begin{array}{c}18,8 \% \\
(0,060)\end{array}$ & $\begin{array}{l}20,2 \% \\
(0,061)\end{array}$ & $\begin{array}{c}16,9 \% \\
(0,058)\end{array}$ & $\begin{array}{l}14,2 \% \\
(0,057)\end{array}$ & $\begin{array}{c}38,3 \% \\
(0,047)\end{array}$ & $\begin{array}{l}35,8 \% \\
(0,044)\end{array}$ & $\begin{array}{c}31,4 \% \\
(0,049)\end{array}$ & $\begin{array}{c}31,2 \% \\
(0,048)\end{array}$ & $\begin{array}{c}27,2 \% \\
(0,074)\end{array}$ & $\begin{array}{l}26,2 \% \\
(0,070)\end{array}$ & $\begin{array}{l}25,1 \% \\
(0,065)\end{array}$ & $\begin{array}{l}24,2 \% \\
(0,064)\end{array}$ \\
\hline & 16.959 & 16.255 & 12.494 & 12.573 & 13.282 & 13.186 & 10.880 & 10.979 & 18.744 & 18.732 & 15.415 & 15.623 & 23.656 & 23.645 & 19.663 & 19.800 \\
\hline AFMCA«AIC & $\begin{array}{c}1,9 \% \\
(0,055)\end{array}$ & $\begin{array}{c}1,4 \% \\
(0,058)\end{array}$ & $\begin{array}{c}0,6 \% \\
(0,068)\end{array}$ & $\begin{array}{c}0,2 \% \\
(0,067)\end{array}$ & $\begin{array}{c}8,7 \% \\
(0,046)\end{array}$ & $\begin{array}{c}10,3 \% \\
(0,047)\end{array}$ & $\begin{array}{c}14,2 \% \\
(0,056)\end{array}$ & $\begin{array}{l}13,5 \% \\
(0,055)\end{array}$ & $\begin{array}{c}15,5 \% \\
(0,039)\end{array}$ & $\begin{array}{l}15,6 \% \\
(0,037)\end{array}$ & $\begin{array}{c}13,3 \% \\
(0,040)\end{array}$ & $\begin{array}{c}11,9 \% \\
(0,039)\end{array}$ & $\begin{array}{c}10,2 \% \\
(0,061)\end{array}$ & $\begin{array}{l}12,7 \% \\
(0,059)\end{array}$ & $\begin{array}{c}14,4 \% \\
(0,049)\end{array}$ & $\begin{array}{l}13,3 \% \\
(0,049)\end{array}$ \\
\hline & 16.959 & 16.255 & 12.494 & 12.573 & 13.282 & 13.186 & 10.880 & 10.979 & 18.744 & 18.732 & 15.415 & 15.623 & 23.656 & 23.645 & 19.663 & 19.800 \\
\hline $\begin{array}{l}\text { Según modalidad de } \\
\text { contratación }\end{array}$ & & & & & & & & & & & & & & & & \\
\hline AFMCT « AFMCA & $\begin{array}{c}11,9 \% \\
(0,028)\end{array}$ & $\begin{array}{c}11,5 \% \\
(0,030)\end{array}$ & $\begin{array}{c}10,0 \% \\
(0,036)\end{array}$ & $\begin{array}{c}10,2 \% \\
(0,036)\end{array}$ & $\begin{array}{c}7,6 \% \\
(0,030)\end{array}$ & $\begin{array}{c}4,2 \% \\
(0,031)\end{array}$ & $\begin{array}{c}2,2 \% \\
(0,034)\end{array}$ & $\begin{array}{c}3,7 \% \\
(0,034)\end{array}$ & $\begin{array}{c}5,0 \% \\
(0,029)\end{array}$ & $\begin{array}{c}3,1 \% \\
(0,029)\end{array}$ & $\begin{array}{c}1,8 \% \\
(0,030)\end{array}$ & $\begin{array}{c}1,9 \% \\
(0,030)\end{array}$ & $\begin{array}{c}18,1 \% \\
(0,044)\end{array}$ & $\begin{array}{l}14,9 \% \\
(0,041)\end{array}$ & $\begin{array}{c}7,5 \% \\
(0,038)\end{array}$ & $\begin{array}{c}7,7 \% \\
(0,037)\end{array}$ \\
\hline & 16.962 & 16.258 & 12.493 & 12.572 & 13.293 & 13.197 & 10.885 & 10.984 & 18.762 & 18.749 & 15.404 & 15.612 & 23.688 & 23.676 & 19.673 & 19.810 \\
\hline $\begin{array}{l}\text { Según sector de } \\
\text { ocupación }\end{array}$ & & & & & & & & & & & & & & & & \\
\hline AFSPub « AFSPriv & $\begin{array}{l}-0,4 \% \\
(0,046)\end{array}$ & $\begin{array}{c}-1,4 \% \\
(0,047)\end{array}$ & $\begin{array}{c}-6,8 \% \\
(0,056)\end{array}$ & $\begin{array}{c}-5,1 \% \\
(0,055)\end{array}$ & $\begin{array}{c}2,4 \% \\
(0,040)\end{array}$ & $\begin{array}{c}2,1 \% \\
(0,041)\end{array}$ & $\begin{array}{c}2,5 \% \\
(0,053)\end{array}$ & $\begin{array}{c}0,7 \% \\
(0,051)\end{array}$ & $\begin{array}{c}-2,0 \% \\
(0,037)\end{array}$ & $\begin{array}{c}-1,8 \% \\
(0,037)\end{array}$ & $\begin{array}{l}-4,5 \% \\
(0,033)\end{array}$ & $\begin{array}{c}-2,8 \% \\
(0,034)\end{array}$ & $\begin{array}{c}-5,0 \% \\
(0,037)\end{array}$ & $\begin{array}{c}-3,9 \% \\
(0,036)\end{array}$ & $\begin{array}{c}-0,6 \% \\
(0,040)\end{array}$ & $\begin{array}{l}-2,5 \% \\
(0,037)\end{array}$ \\
\hline & 17.255 & 16.535 & 12.496 & 12.792 & 13.576 & 13.475 & 10.888 & 11.196 & 20.173 & 20.140 & 15.552 & 16.812 & 25.657 & 25.612 & 19.815 & 21.264 \\
\hline $\begin{array}{l}\text { Entre puestos independie } \\
\text { Y puestos asalariados } \\
\text { informales }\end{array}$ & & & & & & & & & & & & & & & & \\
\hline СРPуР«AI & $\begin{array}{c}28,3 \% \\
(0,075)\end{array}$ & $\begin{array}{c}31,7 \% \\
(0,073)\end{array}$ & $\begin{array}{c}17,2 \% \\
(0,083)\end{array}$ & $\begin{array}{c}18,1 \% \\
(0,081)\end{array}$ & $\begin{array}{c}16,5 \% \\
(0,077)\end{array}$ & $\begin{array}{l}11,6 \% \\
(0,075)\end{array}$ & $\begin{array}{c}-7,7 \% \\
(0,098)\end{array}$ & $\begin{array}{c}-3,3 \% \\
(0,095)\end{array}$ & $\begin{array}{c}26,7 \% \\
(0,073)\end{array}$ & $\begin{array}{l}21,9 \% \\
(0,075)\end{array}$ & $\begin{array}{c}3,0 \% \\
(0,091)\end{array}$ & $\begin{array}{c}0,4 \% \\
(0,090)\end{array}$ & $\begin{array}{c}12,9 \% \\
(0,061)\end{array}$ & $\begin{array}{l}14,5 \% \\
(0,062)\end{array}$ & $\begin{array}{c}1,3 \% \\
(0,089)\end{array}$ & $\begin{array}{c}3,9 \% \\
(0,087)\end{array}$ \\
\hline & 10.571 & 10.063 & 8.721 & 8.886 & 9.293 & 9.172 & 8.468 & 8.678 & 15.147 & 15.114 & 12.447 & 12.800 & 16.205 & 16.181 & 13.256 & 13.559 \\
\hline CPOyS«AI & $\begin{array}{c}5,7 \% \\
(0,057)\end{array}$ & $\begin{array}{c}9,7 \% \\
(0,054)\end{array}$ & $\begin{array}{c}5,9 \% \\
(0,057)\end{array}$ & $\begin{array}{c}6,8 \% \\
(0,055)\end{array}$ & $\begin{array}{c}2,2 \% \\
(0,059)\end{array}$ & $\begin{array}{c}0,0 \% \\
(0,055)\end{array}$ & $\begin{array}{l}-8,5 \% \\
(0,059)\end{array}$ & $\begin{array}{c}-6,8 \% \\
(0,058)\end{array}$ & $\begin{array}{c}-4,4 \% \\
(0,052)\end{array}$ & $\begin{array}{l}-7,5 \% \\
(0,050)\end{array}$ & $\begin{array}{l}-12,9 \% \\
(0,048)\end{array}$ & $\begin{array}{l}-12,4 \% \\
(0,048)\end{array}$ & $\begin{array}{l}-14,4 \% \\
(0,047)\end{array}$ & $\begin{array}{l}-13,0 \% \\
(0,046)\end{array}$ & $\begin{array}{l}-17,8 \% \\
(0,049)\end{array}$ & $\begin{array}{l}-20,2 \% \\
(0,050)\end{array}$ \\
\hline & 10.571 & 10.063 & 8.721 & 8.886 & 9.293 & 9.172 & 8.468 & 8.678 & 15.147 & 15.114 & 12.447 & 12.800 & 16.205 & 16.181 & 13.256 & 13.559 \\
\hline CPOyS«AIC & $\begin{array}{c}2,1 \% \\
(0,053)\end{array}$ & $\begin{array}{c}3,5 \% \\
(0,052)\end{array}$ & $\begin{array}{c}2,3 \% \\
(0,059)\end{array}$ & $\begin{array}{c}4,2 \% \\
(0,056)\end{array}$ & $\begin{array}{c}-4,9 \% \\
(0,055)\end{array}$ & $\begin{array}{c}-6,4 \% \\
(0,052)\end{array}$ & $\begin{array}{l}-11,0 \% \\
(0,057)\end{array}$ & $\begin{array}{c}-8,2 \% \\
(0,056)\end{array}$ & $\begin{array}{l}-16,1 \% \\
(0,043)\end{array}$ & $\begin{array}{l}-15,9 \% \\
(0,043)\end{array}$ & $\begin{array}{l}-17,0 \% \\
(0,044)\end{array}$ & $\begin{array}{l}-17,0 \% \\
(0,044)\end{array}$ & $\begin{array}{l}-18,3 \% \\
(0,044)\end{array}$ & $\begin{array}{l}-17,2 \% \\
(0,043)\end{array}$ & $\begin{array}{l}-17,9 \% \\
(0,044)\end{array}$ & $\begin{array}{l}-21,0 \% \\
(0,044)\end{array}$ \\
\hline & 22.759 & 21.760 & 17.389 & 17.771 & 17.952 & 17.796 & 15.052 & 15.471 & 26.728 & 26.675 & 21.938 & 23.343 & 33.557 & 33.500 & 27.517 & 29.133 \\
\hline CPOyS«AINC & $\begin{array}{c}6,6 \% \\
(0,060)\end{array}$ & $\begin{array}{l}10,3 \% \\
(0,059)\end{array}$ & $\begin{array}{c}6,8 \% \\
(0,071)\end{array}$ & $\begin{array}{c}8,7 \% \\
(0,069)\end{array}$ & $\begin{array}{c}2,9 \% \\
(0,065)\end{array}$ & $\begin{array}{c}1,9 \% \\
(0,063)\end{array}$ & $\begin{array}{c}-7,7 \% \\
(0,061)\end{array}$ & $\begin{array}{c}-7,3 \% \\
(0,061)\end{array}$ & $\begin{array}{c}2,8 \% \\
(0,054)\end{array}$ & $\begin{array}{c}0,5 \% \\
(0,053)\end{array}$ & $\begin{array}{l}-0,9 \% \\
(0,055)\end{array}$ & $\begin{array}{c}0,9 \% \\
(0,054)\end{array}$ & $\begin{array}{c}-2,3 \% \\
(0,053)\end{array}$ & $\begin{array}{c}-3,0 \% \\
(0,051)\end{array}$ & $\begin{array}{c}-3,5 \% \\
(0,053)\end{array}$ & $\begin{array}{c}-6,4 \% \\
(0,054)\end{array}$ \\
\hline & 22.759 & 21.760 & 17.389 & 17.771 & 17.952 & 17.796 & 15.052 & 15.471 & 26.728 & 26.675 & 21.938 & 23.343 & 33.557 & 33.500 & 27.517 & 29.133 \\
\hline $\begin{array}{l}\text { Y puestos asalariados } \\
\text { formales }\end{array}$ & & & & & & & & & & & & & & & & \\
\hline $\mathrm{CPPyP} \backsim \mathrm{AF}$ & $\begin{array}{c}14,9 \% \\
(0,082)\end{array}$ & $\begin{array}{l}14,3 \% \\
(0,084)\end{array}$ & $\begin{array}{c}0,9 \% \\
(0,090)\end{array}$ & $\begin{array}{c}4,4 \% \\
(0,090)\end{array}$ & $\begin{array}{c}-7,4 \% \\
(0,097)\end{array}$ & $\begin{array}{l}-8,1 \% \\
(0,095)\end{array}$ & $\begin{array}{l}-15,1 \% \\
(0,093)\end{array}$ & $\begin{array}{l}-13,5 \% \\
(0,088)\end{array}$ & $\begin{array}{c}-1,7 \% \\
(0,086)\end{array}$ & $\begin{array}{c}-1,7 \% \\
(0,085)\end{array}$ & $\begin{array}{l}-11,6 \% \\
(0,086)\end{array}$ & $\begin{array}{c}-8,4 \% \\
(0,084)\end{array}$ & $\begin{array}{l}-1,5 \% \\
(0,079)\end{array}$ & $\begin{array}{c}-4,3 \% \\
(0,074)\end{array}$ & $\begin{array}{c}-4,7 \% \\
(0,084)\end{array}$ & $\begin{array}{c}-6,8 \% \\
(0,081)\end{array}$ \\
\hline & 17.682 & 16.915 & 13.562 & 13.865 & 13.043 & 12.953 & 10.760 & 11.080 & 18.172 & 18.130 & 15.855 & 17.050 & 25.315 & 25.268 & 21.981 & 23.457 \\
\hline $\mathrm{CPOyS} « \mathrm{AF}$ & $\begin{array}{l}-14,0 \% \\
(0.073)\end{array}$ & $\begin{array}{l}-14,2 \% \\
(0,074)\end{array}$ & $\begin{array}{l}-16,3 \% \\
(0,089)\end{array}$ & $\begin{array}{l}-14,1 \% \\
(0.088)\end{array}$ & $\begin{array}{l}-32,5 \% \\
(0,086)\end{array}$ & $\begin{array}{l}-31,3 \% \\
(0,083)\end{array}$ & $\begin{array}{l}-28,8 \% \\
(0,084)\end{array}$ & $\begin{array}{l}-29,2 \% \\
(0.082)\end{array}$ & $\begin{array}{l}-46,6 \% \\
(0,078)\end{array}$ & $\begin{array}{l}-45,6 \% \\
(0.077)\end{array}$ & $\begin{array}{l}-46,2 \% \\
(0,076)\end{array}$ & $\begin{array}{l}-45,0 \% \\
(0,075)\end{array}$ & $\begin{array}{l}-35,5 \% \\
(0,067)\end{array}$ & $\begin{array}{l}-36,8 \% \\
(0,065)\end{array}$ & $\begin{array}{l}-38,1 \% \\
(0,071)\end{array}$ & $\begin{array}{l}-39,4 \% \\
(0,068)\end{array}$ \\
\hline & 17.682 & 16.915 & 13.562 & 13.865 & 13.043 & 12.953 & 10.760 & 11.080 & 18.172 & 18.130 & 15.855 & 17.050 & 25.315 & 25.268 & 21.981 & 23.457 \\
\hline CPOyS « AFMCT & $-14,1 \%$ & $-12,0 \%$ & $-12,3 \%$ & $-10,9 \%$ & $-24,9 \%$ & $-23,5 \%$ & $-27,5 \%$ & $-26,8 \%$ & $-37,4 \%$ & $-36,4 \%$ & $-33,2 \%$ & $-31,5 \%$ & $-44,4 \%$ & $-41,5 \%$ & $-38,4 \%$ & $-39,0 \%$ \\
\hline & $(0,054)$ & $(0,054)$ & $(0,064)$ & $(0,0$ & $(0,0$ & & $(0,057)$ & & $(0,050)$ & & & & & & $(0,048)$ & $(0,048)$ \\
\hline & 22.453 & 21.473 & 17.391 & 17.556 & 17.666 & 17.515 & 15.058 & 15.268 & 25.335 & 25.301 & 21.798 & 22.150 & 31.619 & 31.594 & 27.394 & 27.696 \\
\hline CPOyS«AFMCA & $\begin{array}{c}-3,9 \% \\
(0,059)\end{array}$ & $\begin{array}{c}-3,9 \% \\
(0,061)\end{array}$ & $\begin{array}{c}-6,5 \% \\
(0,073)\end{array}$ & $\begin{array}{c}-4,6 \% \\
(0,071)\end{array}$ & $\begin{array}{l}-16,7 \% \\
(0,061)\end{array}$ & $\begin{array}{l}-19,4 \% \\
(0,058)\end{array}$ & $\begin{array}{l}-24,5 \% \\
(0,066)\end{array}$ & $\begin{array}{l}-22,6 \% \\
(0,064)\end{array}$ & $\begin{array}{l}-34,4 \% \\
(0,058)\end{array}$ & $\begin{array}{l}-35,3 \% \\
(0,055)\end{array}$ & $\begin{array}{l}-33,6 \% \\
(0,057)\end{array}$ & $\begin{array}{l}-32,0 \% \\
(0,056)\end{array}$ & $\begin{array}{l}-26,8 \% \\
(0,062)\end{array}$ & $\begin{array}{l}-26,5 \% \\
(0,059)\end{array}$ & $\begin{array}{l}-31,1 \% \\
(0,057)\end{array}$ & $\begin{array}{l}-31,2 \% \\
(0,057)\end{array}$ \\
\hline & 22.453 & 21.473 & 17.391 & 17.556 & 17.666 & 17.515 & 15.058 & 15.268 & 25.335 & 25.301 & 21.798 & 22.150 & 31.619 & 31.594 & 27.394 & 27.696 \\
\hline Según & & & & & & & & & & & & & & & & \\
\hline $\mathrm{OyS}$ & $\begin{array}{c}19,7 \% \\
(0,081)\end{array}$ & $\begin{array}{l}17,8 \% \\
(0,084)\end{array}$ & $\begin{array}{l}12,5 \% \\
(0,083)\end{array}$ & $\begin{array}{l}14,0 \% \\
(0,082)\end{array}$ & $\begin{array}{c}11,2 \% \\
(0,072)\end{array}$ & $\begin{array}{c}8,6 \% \\
(0,069)\end{array}$ & $\begin{array}{c}8,7 \% \\
(0,079)\end{array}$ & $\begin{array}{c}11,9 \% \\
(0,070)\end{array}$ & $\begin{array}{c}37,7 \% \\
(0,080)\end{array}$ & $\begin{array}{l}35,7 \% \\
(0,084)\end{array}$ & $\begin{array}{l}36,3 \% \\
(0,091)\end{array}$ & $\begin{array}{l}36,3 \% \\
(0,087)\end{array}$ & $\begin{array}{c}26,1 \% \\
(0,067)\end{array}$ & $\begin{array}{l}26,5 \% \\
(0,068)\end{array}$ & $\begin{array}{r}25,8 \% \\
(0,071)\end{array}$ & $\begin{array}{l}25,6 \% \\
(0,067)\end{array}$ \\
\hline & 5.491 & 5.215 & 4.895 & 4.981 & 4.373 & 4.318 & 4.171 & 4.282 & 6.573 & 6.552 & 6.375 & 6.519 & 7.931 & 7.918 & 7.711 & 7.876 \\
\hline $\begin{array}{l}\text { Entre puestos asalaria } \\
\text { informales }\end{array}$ & & & & & & & & & & & & & & & & \\
\hline AIC AINC & $\begin{array}{c}8,0 \% \\
(0,061)\end{array}$ & $\begin{array}{c}11,3 \% \\
(0,060)\end{array}$ & $\begin{array}{l}13,2 \% \\
(0,067)\end{array}$ & $\begin{array}{l}13,3 \% \\
(0,066)\end{array}$ & $\begin{array}{c}9,7 \% \\
(0,065)\end{array}$ & $\begin{array}{c}9,4 \% \\
(0,065)\end{array}$ & $\begin{array}{c}2,8 \% \\
(0,059)\end{array}$ & $\begin{array}{c}0,1 \% \\
(0,058)\end{array}$ & $\begin{array}{c}22,5 \% \\
(0,035)\end{array}$ & $\begin{array}{l}21,0 \% \\
(0,034)\end{array}$ & $\begin{array}{l}18,1 \% \\
(0,038)\end{array}$ & $\begin{array}{c}20,2 \% \\
(0,037)\end{array}$ & $\begin{array}{c}15,6 \% \\
(0,056)\end{array}$ & $\begin{array}{c}13,6 \% \\
(0,054)\end{array}$ & $\begin{array}{c}10,9 \% \\
(0,054)\end{array}$ & $\begin{array}{c}12,6 \% \\
(0,054)\end{array}$ \\
\hline & 17.268 & 16.545 & 12.494 & 12.790 & 13.579 & 13.478 & 10.881 & 11.189 & 20.155 & 20.123 & 15.563 & 16.824 & 25.626 & 25.582 & 19.806 & 21.257 \\
\hline
\end{tabular}

Fuente: elaboración propia sobre la base de datos de la EPH-INDEC.

Nota: se reportan entre paréntesis los errores estándares robustos y bajo éstos, el número de observaciones con el que se estimó cada brecha. 


\section{Anexo 3. Metodología}

\section{Matrices de transición}

Para computar los patrones de movilidad laboral se estimaron, en primer lugar, matrices de transición que resumen la información relativa al flujo de trabajadores entre las distintas categorías laborales consideradas. A partir de ellas es posible tabular la probabilidad condicional $\left(\mathrm{P}_{\mathrm{ij}}\right)$ de encontrar a un trabajador en la categoría ocupacional $\mathrm{j}$ al final del período considerado, dado que el trabajador estuvo en la categoría i al inicio del mismo. Cada fila de la matriz de transición suma uno y los elementos de la diagonal principal reflejan la probabilidad de permanecer en la misma categoría ocupacional al final del período. Sin embargo, estas matrices no permitan observar si las transiciones entre determinadas categorías laborales son altas o bajas porque los desplazamientos de los trabajadores pueden estar afectados por el tamaño de un estado laboral particular. Por ello, se computaron también matrices de transición estandarizadas. El índice estandarizado se estima como:

$$
\frac{P_{i j}}{P_{. j}}=\left(1-P_{i i}\right) V_{i j}\left(1-P_{j j}\right)
$$

Donde $\mathrm{P}_{\mathrm{ij}}$ es la probabilidad de encontrar a un trabajador en la categoría ocupacional $\mathrm{j}$ al final del período considerado dado que el trabajador estuvo en la categoría $\mathrm{i}$ al inicio del mismo; $\mathrm{P}_{\mathrm{j}}$ es el tamaño de la categoría laboral de destino; $\mathrm{P}_{\mathrm{ij}}$ es la probabilidad de permanencia en la categoría laboral $\mathrm{j}, \mathrm{P}_{\mathrm{ii}}$ es la probabilidad de permanencia en la categoría laboral i, y $V i j$, captura la disposición de parte de un trabajador a dejar la categoría laboral i para ingresar a un puesto vacante $j$.

\section{Modelo econométrico de datos en panel con efectos fijos}

El modelo econométrico estimado para computar las brechas salariales entre las distintas categorías laborales consideradas es el siguiente:

$$
w_{i t}=\beta X_{i t}+\phi I_{i t}+\gamma_{t}+\alpha_{i}+\varepsilon_{i t}
$$

Donde $\mathrm{w}_{\text {it }}$ es el logaritmo del ingreso laboral del i-ésimo trabajador en el año t; $X_{\text {it }}$ es el vector de características observables del ocupado y del puesto de trabajo; $\alpha_{i}$ es el conjunto de características 
inobservables del trabajador invariantes en el tiempo; $I_{i t}$ es la variable dummy que indica la categoría laboral del trabajador; $\gamma_{t}$ es una dummy temporal y $\varepsilon_{i t}$ es el término de error que se asume cumple con el supuesto de exogeneidad estricta. El signo y tamaño del parámetro asociado a la dummy $\mathrm{I}_{\text {it }}$ indica el sentido y la magnitud del diferencial salarial promedio que produciría de manera independiente la inserción en un determinado puesto laboral en comparación con otro, es decir, controlando por el efecto de otros atributos personales y otras características del puesto de trabajo.

Como el ingreso laboral se observa solo para aquellos que están empleados y, según los resultados económicos estándares, es probable que la selección dentro de la fuerza laboral o dentro del empleo esté correlacionada con los ingresos laborales potenciales, ${ }^{22}$ se corrigieron las estimaciones de las brechas de ingresos debido a este problema de sesgo de selección. Con este objetivo, siguiendo a Wooldridge (1995), se estimó la siguiente ecuación de selección, que se supone presenta la forma Tobit para datos de panel:

$$
h_{i t}=\max \left(0, X_{i} \psi_{t}+v_{i t}\right)
$$

Donde $h_{\text {it }}$ son las horas trabajadas; $v_{i t} \mid X_{i t} \quad w_{i t}$ es observado si $\mathrm{h}_{\mathrm{it}}>0$. Bajo el supuesto de que para algún efecto inobservado $g_{i}$, $E\left(\varepsilon_{i t} \mid X_{i}, \alpha_{i}, g_{i}, v_{i t}\right)=E\left(\varepsilon_{i t} \mid g_{i}, v_{i t}\right)=g_{i}+\rho v_{i t}$, se tiene que:

$$
E\left(w_{i t} \mid X_{i}, \alpha_{i}, g_{i}, v_{i t}\right)=\beta X_{i t}+\phi I_{i t}+\gamma_{t}+\rho v_{i t}+f_{i}
$$

Donde $f_{i}=\alpha_{i}+g_{i}$. Por lo tanto, la estimación de (3) por efectos fijos utilizando los datos de panel produciría estimaciones consistentes de $\beta, \phi y \rho$. Para esto, se reemplazan los términos de error $v_{i t}$ por los residuos Tobit $\hat{v}_{i t}$, obtenidos de la estimación de la ecuación (2) ${ }^{23}$ a partir de los $\mathrm{T}$ datos de sección cruzada que conforman el panel.

Con el objetivo de comprobar si el modelo de efectos fijos es más adecuado que el de efectos aleatorios se computó el test de Hausman (1978) a partir de datos de panel para el período 1995-2011 que determina si las diferencias entre dos estimaciones son sistemáticas y

\footnotetext{
22 Para más detalles, véase Heckman (1979) y Vella (1998).

${ }^{23}$ En el modelo Tobit de las horas trabajadas se incluyeron como variables explicativas la edad, el sexo, la educación, el estado civil, la asistencia a un establecimiento educativo, la presencia de un jefe y cónyuge de hogar ocupados y el número de niños o niñas menores de 5 años en el hogar.
} 
significativas. Se emplea fundamentalmente para determinar si un estimador, en este caso el estimador de efectos fijos, es consistente. La estadística del test se computa como:

$$
H=\left(\beta_{c}-\beta_{e}\right)^{\prime}\left(V_{c}-V_{e}\right)^{-1}\left(\beta_{c}-\beta_{e}\right), \quad H \sim X_{n}^{2}
$$

Donde $\beta_{c}$ es el vector de estimaciones correspondientes al estimador consistente, $\beta_{c}$ es el vector de estimaciones que corresponden al estimador eficiente, $V_{c}$ es la matriz de covarianzas del estimador consistente y $\mathrm{V}_{\mathrm{e}}$ es la matriz de covarianzas del estimador eficiente.

Los resultados obtenidos de implementar el test de Hausman que se observan en el siguiente Cuadro para cada uno de los modelos salariales considerados, indican un p-value menor a 0.01 , por lo tanto en todos los casos es posible rechazar la hipótesis nula de igualdad entre el estimador de efectos fijos y el estimador de efectos aleatorios, al 99\% de confianza. Esto justifica la elección de los estimadores de efectos fijos.

\section{Resultados del test de Hausman para los modelos salariales} estimados

\begin{tabular}{lcccc}
\hline Modelos & $\mathbf{1 9 9 5 - 1 9 9 6}$ & $\mathbf{2 0 0 0 - 2 0 0 1}$ & $\mathbf{2 0 0 6 - 2 0 0 6}$ & $\mathbf{2 0 1 0 - 2 0 1 1}$ \\
\hline AF vs AI & 721,85 & 1097,88 & 1475,84 & 1019,82 \\
& $(0,000)$ & $(0,000)$ & $(0,000)$ & $(0,000)$ \\
AI vs AFMCA/AFMCNA & 727,02 & 943,17 & 1270,78 & 630,75 \\
& $(0,000)$ & $(0,000)$ & $(0,000)$ & $(0,000)$ \\
AINC vs AIC & 727,02 & 943,17 & 1270,78 & 630,75 \\
& $(0,000)$ & $(0,000)$ & $(0,000)$ & $(0,000)$ \\
AI vs CPPyP/CPOyS & 732,42 & 893,56 & 1500,68 & 796,74 \\
& $(0,000)$ & $(0,000)$ & $(0,000)$ & $(0,000)$ \\
AFSPU vs AFSPR & 334,76 & 532,81 & 530,63 & 303,84 \\
& $(0,000)$ & $(0,000)$ & $(0,000)$ & $(0,000)$ \\
CPPyP vs CPOyS & 827,88 & 1003,72 & 1662,60 & 835,27 \\
& $(0,000)$ & $(0,000)$ & $(0,000)$ & $(0,000)$ \\
AIC vs AFMCA & 205,17 & 342,73 & 244,81 & 163,57 \\
& $(0,000)$ & $(0,000)$ & $(0,000)$ & $(0,000)$ \\
AINC vs AFMCA & 646,27 & 820,11 & 1191,72 & 598,29 \\
\multirow{2}{*}{ AIC vs CPOyS } & $(0,000)$ & $(0,000)$ & $(0,000)$ & $(0,000)$ \\
& 971,14 & 1097,11 & 1396,42 & 874,62 \\
AINC vs CPOyS & $(0,000)$ & $(0,000)$ & $(0,000)$ & $(0,000)$ \\
& 752,66 & 849,66 & 1135,28 & 703,06 \\
AFMCT vs CPOyS & $(0,000)$ & $(0,000)$ & $(0,000)$ & $(0,000)$ \\
AFMCA vs CPOyS & 734,31 & 805,83 & 1034,08 & 582,87 \\
& $(0,000)$ & $(0,000)$ & $(0,000)$ & $(0,000)$ \\
& 734,31 & 805,83 & 1034,08 & 582,87 \\
& $(0,000)$ & $(0,000)$ & $(0,000)$ & $(0,000)$ \\
\hline
\end{tabular}

Fuente: elaboración propia sobre la base de datos de la EPH-INDEC.

Nota: entre paréntesis se reportan los p-values correspondientes a cada estadística. 